Florida International University FIU Digital Commons

\title{
Romantic Relationships and Adjustment in Early Adulthood: The Role of Cross-sex Experience in the Context of Social Norms and Support
}

Hod Tamir

htami001@fiu.edu

DOI: $10.25148 /$ etd.FI15032111

Follow this and additional works at: https://digitalcommons.fiu.edu/etd

Part of the Developmental Psychology Commons, and the Social Psychology Commons

\section{Recommended Citation}

Tamir, Hod, "Romantic Relationships and Adjustment in Early Adulthood: The Role of Cross-sex Experience in the Context of Social Norms and Support" (2015). FIU Electronic Theses and Dissertations. 1919.

https://digitalcommons.fiu.edu/etd/1919 


\section{FLORIDA INTERNATIONAL UNIVERSITY}

Miami, Florida

ROMANTIC RELATIONSHIPS AND ADJUSTMENT IN EARLY

ADULTHOOD: THE ROLE OF CROSS-SEX EXPERIENCE IN THE CONTEXT OF

SOCIAL NORMS AND SUPPORT

A dissertation submitted in partial fulfillment of

the requirements for the degree of

DOCTOR OF PHILOSOPHY

in

PSYCHOLOGY

by

Hod Tamir

2015 
To: Dean Michael R. Heithaus

College of Arts and Sciences

This dissertation, written by Hod Tamir, and entitled Romantic Relationships and Adjustment in Early Adulthood: The Role of Cross-sex Experience in the Context of Social Norms and Support, having been approved in respect to style and intellectual content, is referred to you for judgment.

We have read this dissertation and recommend that it be approved.

Robert Lickliter

Nathan Katz

Stacy Frazier

Dionne P. Stephens, Major Professor

Date of Defense: March 25, 2015

The dissertation of Hod Tamir is approved.

\begin{tabular}{r}
\hline $\begin{array}{r}\text { Dean Michael R. Heithaus } \\
\text { College of Arts and Sciences }\end{array}$ \\
\hline Dean Lakshmi N. Reddi \\
University Graduate School
\end{tabular}

Florida International University, 2015 


\section{DEDICATION}

This work is dedicated to my family:

Chaya,

Over the past decade our love, friendship, and commitment has blossomed. You have been a constant source of support. We did a lot of growing up together, and there is no one I would rather grow up, and grow old, with.

My Children,

Rivka, you fascinate me with your liveliness and joie de vivre. Daniel, you inspire me with your curiosity and sincerity. Noam, you delight me with your energy and sense of adventure. 


\section{ACKNOWLEDGMENTS}

This dissertation could not have been completed without the invaluable support of my advisors Drs. Levitt and Stephens.

Dr. Levitt, for devoting countless hours throughout my graduate experience, from the master's thesis proposal through my dissertation defense. You have had a profound impact on me both professionally and personally, and I can only hope to affect such positive change in others.

Dr. Stephens, thank you for graciously taking me on in my final year. Your insight and optimism have motivated me to get to this point, and your assistance in securing a postdoctoral postion is greatly appreciated.

I would also like to thank my committee members, Drs. Lickliter, Frazier, and Katz for your feedback and support, and for taking the time to review, edit, and critique my work. 


\begin{abstract}
OF THE DISSERTATION
ROMANTIC RELATIONSHIPS AND ADJUSTMENT IN EARLY

ADULTHOOD: THE ROLE OF CROSS-SEX EXPERIENCE IN THE CONTEXT OF

SOCIAL NORMS AND SUPPORT
\end{abstract}

by

Hod Tamir

Florida International University, 2015

Miami, Florida

Professor Dionne P. Stephens, Major Professor

Attachment and interpersonal theory suggest a sequential pattern of relationships

beginning in the earliest stage of development and progressing to social and eventually romantic relationships. Theoretically, cross-sex experiences have an important role in the progression of interpersonal relationships. Despite the prevalence of these theories about the nature of romantic relationship development, the linkage of cross-sex experience (CSE) to romantic relationships has not been established. Indeed, it is an intuitive assumption, especially within Western society and these theories do not consider sociocultural factors that may influence CSE and relationship satisfaction. This study addresses the varying contextual factors that may contribute to relationship satisfaction and adjustment, aside from CSE, and is divided into two parts. Study 1, addresses CSE, relationship satisfaction, and adjustment in a unique population, ultra-Orthodox Jews. Among this population, social or romantic CSE is limited and sexes are effectively segregated. Study 2, expanded the study to a larger sample of U.S. college students, to assess the linkage of CSE to romantic relationship satisfaction in a more typical Western 
population. It included social norm and support variables to address the contextual nature of relationship development and satisfaction. Results demonstrated clear differences in the relation between CSE and relationship satisfaction in the two samples. In the first sample CSE was unrelated to relationship satisfaction; nevertheless, relationship satisfaction was associated with adjustment as it is for more typical populations with greater CSE. These results suggested the importance of specifying how social norms and social support relate to CSE, relationship satisfaction and adjustment. The results from the second sample were consistent with the theoretical framework upon which the social/romantic literature is based. CSE was directly connected to relationship satisfaction. As anticipated, CSE, relationship satisfaction, and adjustment also varied as a function of social norms and support. These findings further validate the influence of socio-cultural factors on relationship satisfaction and adjustment. This study contributes to the romantic relationship literature and broadens our understanding of the complex nature of interpersonal and romantic relationships. 


\section{TABLE OF CONTENTS}

CHAPTER

PAGE

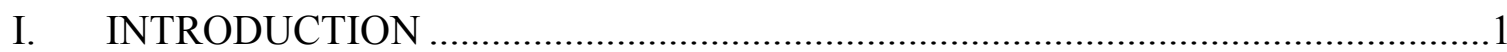

II. LITERATURE REVIEW ...........................................................................

Life Span Social Development Theory............................................................ 7

The Development of Romantic Relationships ......................................................

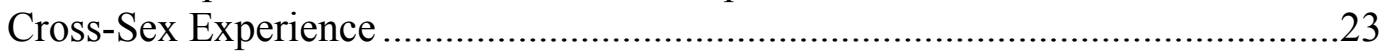

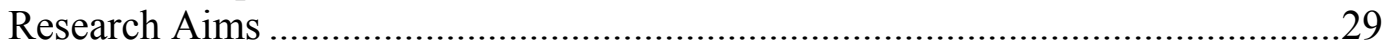

Hypotheses....................................................... 30

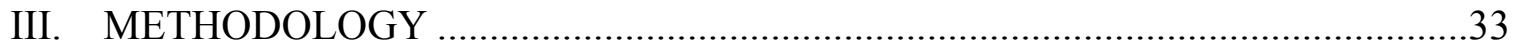

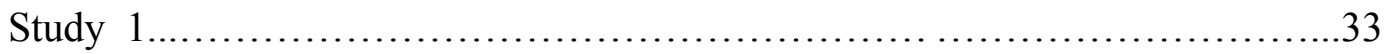

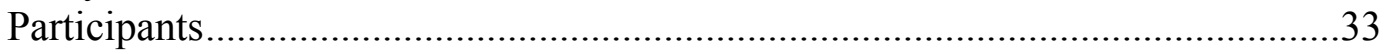

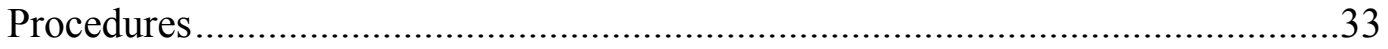

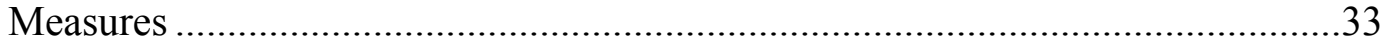

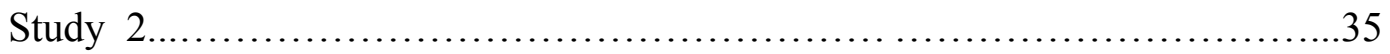

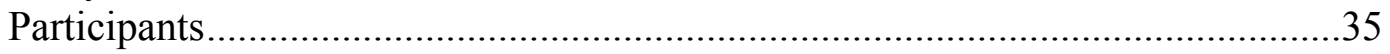

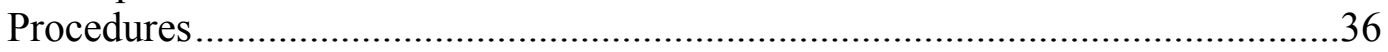

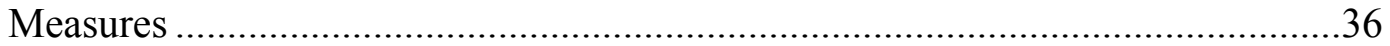

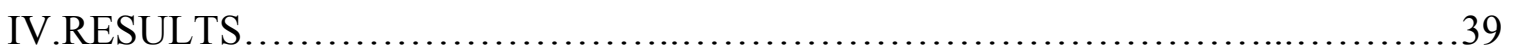

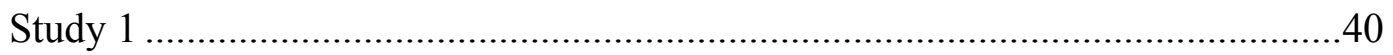

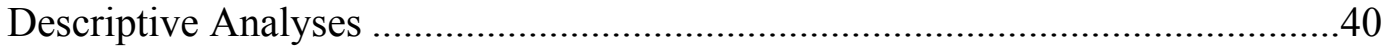

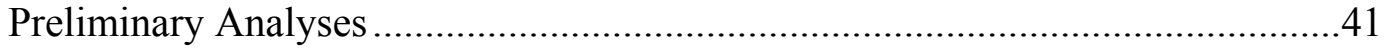

Notes for Model Fit and Model Fit Statistics.......................................................41

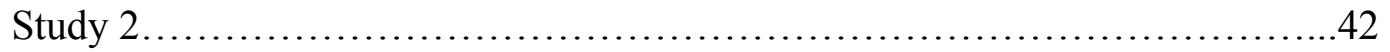

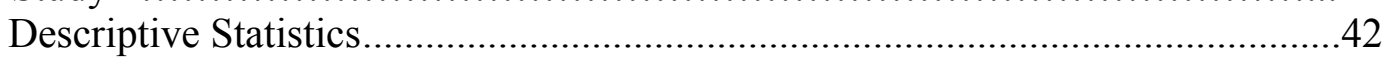

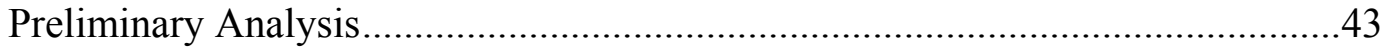

Notes for Model Fit and Model Fit Statistics....................................................44

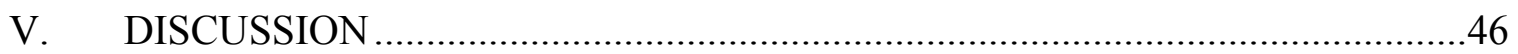

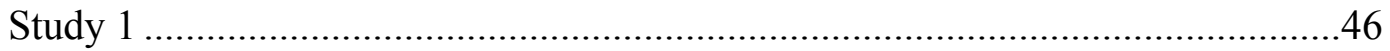

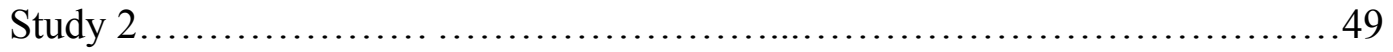

General Discussion ..................................................... 52

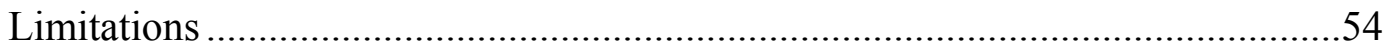

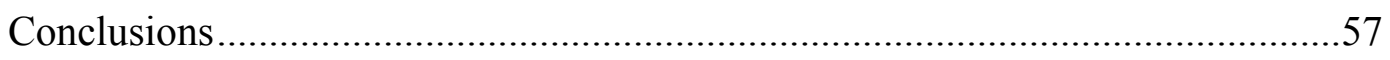

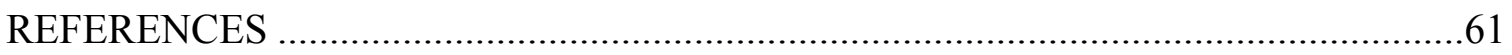

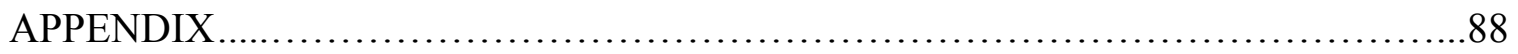

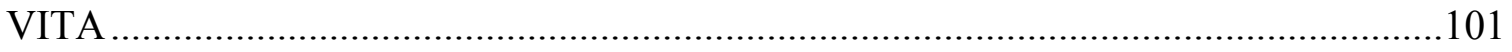




\section{LIST OF TABLES}

TABLE

PAGE

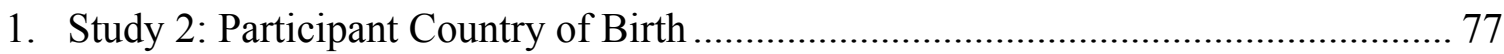

2. Study 1: Means and Standard Deviation of Variables ............................................ 78

3. Study 1: Correlation Coefficient Values (Pearson) of Variables ............................. 79

4. Study 1: 95\% Confidence Intervals for Unstandardized Path Coefficients.............80

5. Study 2: Means and Standard Deviation of Variables .......................................... 81

6. Study 2: Correlation Coefficient Values (Pearson) of Variables.............................. 82

7. Study 2: 95\% Confidence Intervals for Unstandardized Path Coefficients ............... 83 


\section{INTRODUCTION}

Following Bronfrenbrenner's (1979) ecological systems theory and Vygotsky's (1978) sociocultural theory, many studies have highlighted the fundamental role of social, cultural and ecological context on human development. More recently studies on social networks (Kahn \& Antonucci, 1980; Levitt, Guacci-Franco, \& Levitt, 1993; Takahashi, Ohara, Antonucci, \& Akiyama, 2002) have addressed support, friendship, romantic relationships, and general wellbeing. Socio-cultural contributors to development, particularly family, ethnicity, and religion, were considered in the present study. More specifically, the study addressed the extent to which endorsement of ethnic, familial, and religious norms and social support impact the development of romantic relationships and adjustment in early adulthood.

Over the past half-century, the U.S. has seen an influx of immigrants, with many arriving from non-European countries, including Latin America and the Caribbean. (Portes \& Rumbaut, 2001, 2006). The wave of immigration has led to increased multiculturalism and ethnic diversity within the U.S. (Huntington, 2004; Stepick, DuttonStepick, \& Vanderkooy, 2011) and the presence of numerous sub-cultures within the overarching U.S culture. These sub-cultures may hold social norms that differ from those of the general population. Familism, for example, has been cited as an important part of Hispanic culture (Sabogal, Marin, Otero- Sabogal, Marin, \& Perez-Stable, 1987). Additionally, Saroglou and Cohen (2011) describe the enmeshed relationship between culture and religion, which introduces an additional dimension of societal norms.

Theoretically, a link between social norms and the development of close relationships has been posited by Levitt (1991, Levitt, Coffman, Guacci-Franco, \& 
Loveless, 1994). Comparable to other social relations theories (for example, Bowlby, 1969; Takahashi, 2005), in Levitt's Social Expectations Model, interactions with social network members, beginning in infancy, build expectations about relationships that carryover into the formation of later relationships, including those with romantic/marital partners. As individuals develop cognitively, they are able to store and maintain relationship expectations based on prior social interactions. At the same time, they also develop the ability to understand and integrate culturally defined social norms. Thus, direct interactions are primary building blocks, but, with cognitive maturation, relationships are also influenced by social norms governing interpersonal roles. As rolebased expectations are often life stage related and culture specific, they tend to vary across age and culture, promoted by the interconnected values, attitudes, and behaviors of individuals' social networks.

One important area of cultural and religious divergence is in norms regarding cross-sex experience (CSE) in childhood and adolescence. Theoretically, within the literature on social and personal development, cross-sex relationships have been considered part of the general progression from sex-cleavage in childhood to mate selection in adulthood. For example, Sullivan's (1953) theory of interpersonal development emphasizes the importance of social relationships, positing that peer relationships become increasingly intimate in adolescence, with romantic relationships merging intimacy and lust to develop loving relationships in late adolescence. The ability to form lasting relationships in adolescence is then thought to contribute to adult relationship skills. 
Similarly researchers examining adolescent relationships (Collins, Christian, \& Hennighausen, 2000; Schmit, 1995) report that positive relations with peers and parents in adolescence predict successful adult romantic relationships. Notably, Meier and Allen (2009) reported that romantic experience in adolescence is associated with the likelihood of cohabitation in early adulthood, and having a steady romantic partner in adolescence is predictive of marriage in early adulthood.

Thus, CSE and romantic involvement in adolescence are thought to be important factors in development, especially concerning the establishment of intimate adult relationships. However, most research and theory-building efforts in this area are taken from the predominant European-origin U.S. population. As with all normative trajectories, individuals can be expected to deviate from the outlined steps, especially when these are compounded with social or cultural conditions (Cohen, Kasen, Chen, Hartman \& Gordon, 2003). Families, ethnic groups, and/or religious groups may convey divergent societal norms regarding dating, intimacy, and romantic experience that may alter the trajectory of relationship development experienced normatively within the U. S. population.

In general, social relationships, especially close, intimate social bonds, have been linked clearly and significantly to personal adjustment (George, 2006). Research indicates that individuals with positive, supportive social relationships have higher selfesteem, less depression, and, in general, better mental and physical health than those lacking such relationships (Thompson \& Helller, 1990; Matt \& Dean, 1993). Thus, as our demographics continue to diversify, it is increasingly important to understand how 
social relationships develop and how they link to personal well-being within diverse cultural contexts.

An initial study, conducted as part of this dissertation (Study 1), addressed variations in cross-sex experiences and the relation of cross-sex experience to marital satisfaction and well-being in a unique population of Orthodox and Ultra-Orthodox Jews. Within this population, there are clearly outlined restrictions on CSE and the genders are effectively segregated before marriage, particularly among the Ultra-Orthodox.

On the basis of literature regarding the general population, cross-sex interaction is thought to be an important component to experiencing and developing social and romantic relationships. Conversely, limiting such interaction may generate negative outcomes for relationship stability and marital satisfaction. However, the social context in which these experiences occur must be considered in achieving a general understanding of the literature. Mitigating factors, such as religious practice and support, may offset limited social and romantic experiences in religious communities.

Thus, the goals of Study 1 were to document the phenomenon of sex-segregation within the religious-cultural context of Orthodox Judaism and to assess the effect of gender segregation on marital satisfaction and personal adjustment for this population. The results provided a baseline for understanding divergent societal norms that are atypical in the general population, but are not indicative of social or developmental problems within a specific cultural context.

Specifically, for this sample of Orthodox and Ultra-Orthodox Jews, marital satisfaction was associated with personal adjustment, as it is in more typical U.S. populations. However, cross-sex experience was not linked to relationship satisfaction or 
adjustment for this culturally divergent group. A plausible explanation for this outcome is that limits on pre-marital cross-sex experience are normative for this population, so that expectations regarding marital partners are derived from factors other than prior experience with dating or other aspects of cross-sex interaction. High levels of support within this population may also contribute to individual endorsement of normative restrictions and a consequent disconnect between cross-sex experience and marital relationship expectations.

The findings of Study 1 suggested the need to expand the research to a diverse population including multiple races, ethnicities, and religions, which may be more representative of normative patterns in social and romantic developmental trajectories in the United States. Thus, Study 2 included a multi-cultural sample of university students. The range of predictor and outcome measures was also extended to attempt to capture the phenomena leading to intimate relationship commitment and satisfaction for individuals from diverse cultural and religious backgrounds. Variations in support from members within family and social networks were addressed. Associations of cultural, religious, and familial norms to cross-gender experience, relationship satisfaction, and adjustment were also addressed.

Specifically, predictive measures in Study 2 included indices of religious, ethnic/cultural, and familial norms regarding cross-sex experience in childhood and adolescence held by the groups to which participants belong (Social Norms). There are differences in normative expectations between Orthodox and Ultra-Orthodox Jewish denominations, but social norms were not measured directly in Study 1. The addition of indices of cultural, religious, and familial norms in Study 2 enabled an assessment of the 
extent to which social norms predict the extent of individuals' cross-sex experience and whether normative expectations also predict relationship and adjustment outcomes.

Study 2 also included measures of social support received by participants from their religious, ethnic/cultural, and family groups (Social Support). The inclusion of the support measures was inspired by the idea that the impact of social norms on cross-sex experience would vary depending on the extent to which individuals received support from the sources of normative expectations. In other words, those receiving high levels of support from their family, ethnic/cultural, or religious groups would be more likely to base their actual cross-sex behavior on the norms held by their group(s).

Both Study 1 and Study 2 measured the amount of childhood and adolescent cross-sex experience reported by participants (CSE). Outcome measures included indices of relationship satisfaction and adjustment, although the relationship satisfaction measures differed between the two studies.

A marital satisfaction scale was used in Study 1, as intimate, romantic relationships typically exist primarily within marriage for Ultra-Orthodox Jews, who tend to marry relatively early in adulthood. A more general relationship satisfaction measure was used in Study 2 which employed a more typical sample of young adult college students who are more likely to be in premarital romantic relationships and to marry later.

The adjustment measure used in both studies was a scale assessing individuals' levels of depression, anxiety, and stress. The following literature review includes a review of research findings relevant to the predictor and outcome variables included in the present study. 


\section{LITERATURE REVIEW}

This review of the literature begins with a brief overview of the life span social developmental theory in which the present research is grounded. This overview is followed by summations of research on the development of romantic relationships, variation in cultural norms and practices regarding cross-sex interaction, the role of social support in relationship development and personal adjustment, and linkages of relationship commitment and quality to adjustment.

\section{Life Span Social Developmental Theory}

In some ways, the past 60 years may be viewed as a golden age for socialdevelopmental psychology. Great strides have been made in this relatively young field. Works of Erikson, Bowlby, Bronfenbrenner, Cairns, Lewis, Sullivan and others have been used as a basis for many subsequent studies and discoveries in this field. Yet, there is still a dearth of literature that addresses the specific changes and variations of development that occur within and across stages or phases of the life span.

For example, adulthood is often a developmental stage that receives general statements and assumptions about social relationships, yet there are clearly differences between a 20,40, or 60-year old. In recent years researchers have taken a more nuanced approach to comprehending challenges and developmental trajectories of varying agecohorts. An example is J.J. Arnett's (2000) work on emerging adulthood.

With respect to social relationships in particular, Diehl, Coyle, \& Labouvie-Vief (1996) challenge the notion that development stagnates at some point in adulthood, yet it can be difficult to address changes in social and romantic relationships across the lifespan when, by and large, theorists tend to focus on a specific developmental stage. 
Erikson (1968) outlined eight stages of development across the lifespan, asserting that life is a perpetual series of conflicts, the results of which have implications in subsequent stages (Rosenthal, Gurney, \& Moore, 1981). The first five stages focus on childhood and adolescence, and the remaining three stages involve adulthood, namely intimacy versus isolation in early adulthood, generativity versus stagnation in middle adulthood, and integrity versus despair in older adulthood.

Erikson's stage theory has spawned many studies that have bolstered his theory; however some studies have demonstrated a variance in time and tempo of crises and some participants have reported no crises at all. This variation may be attributed to changes in society, particularly involving people who do not come from a dominant Western society (Diehl, Coyle, \& Labouvie-Vief, 1996).

Furthermore, an individual's life course is greatly influenced by socio-cultural, historic, life-events (e.g. Baltes, Reese, Lipsitt, 1980; Elder, 1985). Cultural and ethnic membership can also strongly influence perceived norms and expectations (Billingsley, 1992; Doherty, Hatfield, Thompson, \& Choo, 1994).

\section{The Development of Romantic Relationships}

Much of the work on the development of romantic relationships has been based on attachment theory. However, social network models may be more relevant to understanding cultural variation in patterns or trajectories of romantic relationship development. This section begins with an overview of attachment theory, followed by a consideration of the social network perspective. Theoretical and empirical work addressed specifically to the development of romantic relationships is then reviewed. 


\section{Attachment Theory}

The seminal works of Bowlby (1969) and Ainsworth (1989) generated much interest and subsequent research on infant-caregiver attachment. Bowlby's theory emerged from Freud's psychoanalytic writing regarding the significance of the infantcaregiver relationship as a foundation for the development of subsequent social relationships, but then joined psychoanalytic theory to an ethological systems theory, suggesting that infants and caregivers are evolutionarily prepared to engage in interactions that promote infant (and species) survival.

He further proposed that ongoing interactions with caregivers become represented as affective-cognitive "working models" that carry over into expectations regarding other social relationship partners. Following Bowlby, subsequent attachment researchers have emphasized the relation between infant and primary caregiver as the starting point for the development of attachment representations (Ainsworth, Blehar, Waters, \& Wall, 1978; Bretherton \& Munholland, 1999; Rothbard \& Shaver, 1994).

Bowlby initially thought of attachment theory as applicable to life-long social bonding and other theorists have sought to extend attachment theory to the life span (Ainsworth, 1989; Antonucci, 1976). However, attachment theory, with its emphasis on infantile attachment as a prototype for later relationships, is limited with respect to predicting or explaining adult relationship development. A number of theorists have suggested that an understanding of attachment must evolve to include the complex web of relationships that are part of a social network (Antonucci, 2009, Levitt, 1991; 2005; Levitt \& Cici-Gokaltun, 2011; Lewis, 2005; Takahashi, 2005). 


\section{The Social Network Perspective}

Social networks are complex relational systems providing the primary social contexts for human development (Levitt, 2012). They may include family, friends, coworkers, or others who play an important role in the individual's life. Interest in social networks is a relatively recent trend in developmental psychology, beginning with foundational work by Cochran and Brassard (1979), Lewis (Lewis \& Feiring, 1979; Lewis, 1982), and Kahn and Antonucci (1980). The Kahn and Antonucci (1980) Convoy Model of social relations is a life span developmental model that depicts the social network or convoy as a hierarchical circular structure of relations surrounding the individual throughout life, with persons closest and most important to the individual in the innermost circle.

Significant network members, who form closer bonds than others and develop trusting relationships, and are typically found in the inner circle, often include parents, siblings, and very close friends. Spouses and romantic partners are often among the closest persons in an individual's network. People in the outer area of the convoy may include more distant relatives, friends, teachers, co-workers, or others of some importance to the individual. Interestingly, once inducted into the significant other network, maintenance of these relationships does not necessarily require frequent or lengthy interactions, although intimate relationships are often defined by the extent of intimacy of exchanges and the influence of those interactions (Surrs \& Milardo, 1991).

From the social network perspective, attachment relationships are a subset consisting of those who, in terms of the Convoy Model, are "so close that the individual can't imagine life without them" (Antonucci, 1986; Levitt, 1991). Romantic partners, as 
attachment figures, are part of the individual's social network and romantic relationships are formed, maintained, and sometimes dissolved within the context of interconnected network influences. Furthermore, the network itself exists within a larger socio-cultural milieu, which has implications for the various routes that may be taken to establish romantic and/or marital bonds within any particular cultural context. In general, research on the development of social networks indicates that networks expand from early relationships with a limited number of individuals (typically including parents, grandparents, siblings, and sometimes friends and others) to encompass a broader spectrum of network partners, with a noticeable shift toward the inclusion of greater numbers of peers in early adolescence (Levitt, 2012),

Past theorizing and some empirical work on the development of cross-sex romantic relationships suggest that these relationships emerge in the adolescent years as an outgrowth of peer involvement. Erikson's stage theory (1968) designated key developmental milestones across the lifespan, listing identity formation in adolescence and intimacy in young adulthood as significant developmental tasks. According to Erikson, successfully navigating the adolescent identity crisis is the key to developing intimacy in young adulthood. Adolescents form romantic relationships, but these tend not to be long term committed partnerships. More recently, however, research has suggested that romantic experience in adolescence contributes to identity development (Montgomery \& Sorell, 1998; Sanderson \& Cantor, 1995).

Sullivan's theory of interpersonal development (Sullivan, 1953) also emphasizes the importance of social relationships. Sullivan cited the emergence of same-sex friendships (“chumships") in middle childhood as a meaningful step toward developing 
relationship capacity. He also posited that peer relationships become increasingly intimate in adolescence, when romantic relationships begin to develop, merging intimacy and lust to develop loving relationships in late adolescence. Sullivan viewed the ability to form lasting relationships in adolescence as important to developing adult relationship skills.

More recent theories have been proposed to address how adolescent relationships develop and how they fit into existing social structures. Fuhrman and Wehner (1994) devised a behavioral systems approach to adolescent romance, within four stages: affiliative, sexual/reproductive, attachment, and caregiving. Other theorists (Brown, 1999; Connolly \& Goldberg, 1999) have used a phase-based approach with four distinct phases: Initiation, affiliation, intimacy, and commitment.

There is considerable overlap between the system and phase approaches to adolescent romantic relationships. Both theories outline a normative pattern for adolescent relationship experience, beginning in early adolescence with group dating, continuing into middle adolescence with increased intimacy and separation from the larger peer group, and, in late adolescence, the progression towards committed, intimate relationships for longer durations (Seiffge-Krenke, 2003).

Other researchers examining adolescent relationships (Collins, Christian, \& Hennighausen, 2000; Schmit, 1995) have reported that positive relations with peers and parents in adolescence predict successful adult romantic relationships. Romantic experiences can be viewed as sequential developmental stages (Feinstein \& Ardon, 1973; Mahler, 1973), with adolescent romance serving as a precursor or "practicing" for lasting adult relationships. 
Meier and Allen (2009) confirmed the normative (for the U.S.) trajectory of adolescent romantic relationships, specified by Fuhrman and Wehner, (1994), Brown, (1999), and Connolly and Goldberg (1999), as progressing from limited experience and interaction to more serious intimate relationships over-time. Notably, Meier and Allen (2009) also reported that romantic experience in adolescence is associated with the likelihood of cohabitation in early adulthood, and steady experience (having a steady romantic partner) in adolescence is predictive of marriage in early adulthood.

Thus, inter-gender interaction and romantic involvement in adolescence are thought to be important factors in development, especially concerning the establishment of intimate adult relationships. However, as with all normative trajectories, individuals can be expected to deviate from the outlined steps, especially when these are compounded with social or cultural conditions (Cohen, Kasen, Chen, Hartman \& Gordon, 2003).

Social Network Influence on Romantic Partnerships

Supportive exchanges are a primary function of social networks and almost all of the people within a social network typically provide some support to the individual (Levitt, 1991). Network members also contribute to an individual's self-concept and can influence a person through comments and thoughts shared.

Furthermore, social networks are made up of numerous people who may considerably impact individuals’ views of their partner (Kim \& Stiff, 1991; Blau, 1964). Hence network member approval plays an important role in mate selection and relationship satisfaction. Social network support for romantic partnerships can be expressed in many ways. For example, family members inquiring regarding how a 
relationship is working out would be considered a sign of support, as opposed to family members showing no interest in the success or failure of a relationship. The influence that any particular member of the network yields will likely depend on the network member's role status and closeness to the individual (Levitt, 2005, 2012; Milardo, 1992; Surra \& Milardo, 1991).

However, social network relations are not always supportive and network relations can be quite conflicted (Akiyama, Antonucci, Takahashi, \& Langfahl, 2003). Network members may try to interfere with relationships of which they do not approve, attempting to influence an individual's behavior or outlook (Parks \& Adelman, 1983). Even though interactions between social network members can be infrequent, there are often cues and social references that can influence the individual even without direct interactions.

Guidelines set by the network, expressed via socialization and norms of that particular group, are also an effective method of transmitting information and expectations. Relationship advice, suggestions, and positive feedback conveyed by the network have been associated with greater relationship satisfaction (Johnson \& Milardo, 1984; Kim \& Stiff, 1991). Conversely, social sanctions may be used to convey disapproval, for example of dating someone in a different socio-economic class. Network members may reinforce their opinions by introducing other potential partners that do fall within their social norms (Bates, 1942; Sussman, 1953).

Furthermore, norms are also shared by cues within the group, also called resocialization. For example, an individual who notices that many friends are engaged in serious relationships may be prompted to settle down as a result of perceived social 
norms (Surra \& Milardo, 1991). Resocialization can also occur in a less direct manner, as standards, values, and attitudes shared over extended periods of time tend to influence behavior (Milardo \& Lewis, 1985). Important components of a relationship, such as love, satisfaction, and commitment are also influenced by societal norms transmitted through personal social networks (Kim \& Stiff, 1991; Sprecher, 1998; Johnson \& Milardo, 1984).

\section{Ethnic/Cultural Diversity in Social Networks and Support}

Some research with culturally diverse groups has addressed the relation of family support to romantic relationship formation. Studies on ethnic family support and romantic relationships in Anglo-European, Hispanic-Latino, and African American samples have yielded varying results.

In one study, college students reported that parents were more likely to express positive regard when they approved of their child's partner. These parents were also more polite, inviting and encouraging towards approved participants' partners (Parks \& Adelman, 1983). Another study with an Anglo-European American sample reported family and friend support as predictors for emotional attachment and likelihood to continue relationships (Parks, Stan, \& Eggert, 1983).

When assessing social networks across racial and ethnic samples, some studies suggest that Anglo-European Americans may be influenced less than non-AngloEuropeans, possibly due to a more individualistic and autonomous focus within their networks. In a study evaluating Individualism versus Collectivism, Doherty, Hatfield, Thompson, and Choo (1994) found that Anglo-European Americans were significantly 
more individualistic than other racial/ethnic groups. In general, Anglo-European Americans also tend to have fewer kin in their networks (Ingoldsby, 1995).

Despite the broad range of diversity amongst Hispanics/Latinos in the U.S. , studies with Hispanic-Latino American participants have consistently demonstrated a strong emphasis on family or familism (McRoy, 1996; Locke, 1992). In this context, familial loyalty may have a greater effect on an individual's attitudes and behavior (Sabogal, Marin, OteroSabogal, 1987), related to support received from the family network (Christopher, Johnson \& Roosa, 1993).

Similarly, studies with African American participants report strong family ties (Billingsley, 1992). African Americans are more likely to live in extended family households than Anglo-European Americans (Taylor, Chatters, Tucker, \& Lewis, 1990; Logan, 1990). Non-kin relations are less dependable than kin relationships and therefore opinions of friends may be less valued than those of family members who share a stronger bond (Ellison, 1990). As in other U.S. ethnic minority subcultures, family is often a great source of support for African Americans (King, 1995; Taylor, Chatters, \& Jackson, 1993).

Thus, characteristics of social networks and the cultural socialization they convey vary across diverse cultures and ethnicities. The present study included a multicultural sample of young adults in an attempt to better understand socio-cultural influence on romantic relationships. Socio-cultural influence factors examined in the study include social norms conveyed through the individual's religious, ethnic, and familial background and the social support derived by the individual through religious, ethnic, and familial channels. 
Social Support, Relationship Quality, and Personal Adjustment

Numerous studies have linked social support to personal adjustment and wellbeing (Cohen \& Willis, 1985, for a review; Markides \& Martin, 1979). Although individuals typically derive much of their support from close family and friend relationships (Levitt, 1991), support derived through ethnic group and religious affiliations may also play a role.

With respect to emerging adults, parental support has often been linked to psychological adjustment (e.g. Hoffman \& Weiss, 1987; Levitt, Silver, \& Santos, 2007; Rice, Cole, \& Lapsely, 1990). Support has also been related to adaptive and social behavior in early adulthood (Holahan, Valentiner, \& Moos, 1994).

In general, there is a relationship between early-life family experiences and later outcomes, such as sociability. Maughan and Champion (1990) reported on the importance of support in earlier stages of life and its impact on aspects of the transitional stages of young adulthood, like social network and relationship development. In fact several studies have reported on the relationship between positive parenting and social orientation in young adulthood (Bartholomew \& Horowitz, 1991; Langston \& Cantor, 1989). Family support during stressful life events has consistently been related to more positive adaptive outcomes (Hobfoll \& Spielberger, 1992; Holahan \& Moos, 1987, 1990, 1991).

In addition to support, satisfying social relationships have been related to health and overall wellbeing (Heinrich \& Gullone, 2006). For example, researchers have reported greater subjective well-being among married persons than in never married or 
previously married individuals (Glenn \& Weaver, 1979; Gove, Style, \& Hughes, 1990; Mastekaasa, 1994; Veenhoven, 1984).

Numerous reasons for why married participants report greater well-being have been offered. Marriage often provides companionship (Glenn, 1975) and confiding in a spouse, thus lessening stress and increasing ability to cope (Gove et al, 1990). It may also provide couples with a positive identity (Gove \& Umberson, 1985). Emotional support that is associated with marriage is also connected with well-being (Williams, 1988).

Links between romantic relationships and well-being have also been found. Campbell, Sedikides, and Bosson (1994) studied romantically involved and nonromantically involved college students with respect to their self views and adjustment. Romantically involved students reported self-images closer to their ideal selves and better adjustment on a scale of psychological well-being. Conflict in young adult romantic relationships has been linked to depression (Marchand-Reilly, 2009). Approaching the topic from an Eriksonian perspective on the importance of establishing intimate relationships in early adulthood, Paul, Poole, and Jakubowyc (1998) found that freshman students who established a romantic relationship were better adjusted than those with no romantic involvement or those who clung to their pre-college romances.

Of particular interest is survey research by Kamp-Dush and Amato (2005) comparing the subjective well-being of individuals with a range of relationship statuses. Participants were the young adult children of individuals who had been interviewed earlier as part of a national survey of married respondents. The results indicated first that the highest levels of well-being were reported by married individuals, followed by those who were cohabiting, those with steady dating partners, and those who were dating 
casually. Those who dated infrequently or not at all were least adjusted. Relationship quality (happiness) was also related to well-being, independent of the participants' level of relationship commitment, suggesting that both commitment and quality of relationships are important to consider in predicting adjustment.

One aspect of well-being studied rather extensively is loneliness. Loneliness relates specifically to social relationships, (Green, Richardson, Lago, \& Schatten-Jones, 2001) and comes about when there is incongruity between actual relationships and preferred relationships (Peplau \& Perlman, 1982).

Although loneliness is reported at various stages throughout the lifespan, young adults often report increased loneliness (Heinrich \& Gullone, 2006; Perlman \& Landolt, 1999). Parlee (1979) reported that $71 \%$ of $18-24$ year-olds feel lonely sometimes. This is particularly interesting considering that this is the age when young adults often attend college, suggesting that the transition to college often relates to loneliness. In fact, college freshman do report considerable loneliness (Berman \& Sperling, 1991) and loneliness is related to depression (Joiner, 1997). Parental support is related to reduced loneliness among college students (Levitt et al., 2007; Mounts, Valentiner, Anderson, \& Boswell, 2006), but romantic relationships may also play a role.

Societal fixation on having a romantic relationship may augment loneliness in the "uncoupled" (Ponzetti, 1990). As romantic relationships become more important in late adolescence, teens often describe romantic partners as their primary source of social support (Monck, 1991). In studying the significance of romantic relationships among college students, Green et al. (2001) found higher rates of loneliness among uncoupled 
students compared to coupled students. A Turkish university study reported similar results (Deniz, Hamarta, \& Ari, 2005).

As noted previously, peers increase in importance in early adolescence and adolescents tend to spend less time with family and more time with friends (Larson, 1999). Some research suggests the best predictor of loneliness is the absence of friends (Pierce, Sarason, \& Sarason, 1991). In fact the need for friends may be more important than the need for a romantic partner (Cutrona, 1982).

\section{Research on Religious Support and Normative Experience}

As religion often plays a significant role in the extent to which children experience cross-sex interaction and in variations in family and ethnic values regarding adolescent romance, religious norms and support are of particular interest in the present

research Aspects of religion have been associated both with general well-being and with marital satisfaction. Furthermore, marital satisfaction is linked to other positive outcomes, including personal adjustment. Literature relevant to these areas is reviewed in this section.

\section{Religion and Adjustment}

Despite theoretical assertions by early leaders in psychology that religiosity exacerbates symptoms of anxiety (e.g., Ellis, 1988; Eysenck, 1981; Freud 1943), the majority of empirical studies over the past four decades have indicated that greater basic religious observance such as church attendance and religious study are associated with decreased anxiety (Koenig, Ford, George, Blazer, \& Meador, 1993; Williams, Larson, Buckler, Heckmann, \& Pyle, 1991). Religious practices have also been linked to enhanced levels of coping with life struggles (see Myleme, Koenig, Hays, Eme-Akwari, 
\& Pargament, 2001 for a review), and decreased post-traumatic stress symptoms (Graham-Bermann, DeVoe, Mattis, Lynch, \& Thomas, 2006; Watlington \& Murphy, 2006).

Positive qualities of religion have been reported in numerous studies. Religion has been associated with various health benefits, including physical and mental health (Koenig, McCoullough, \& Larson, 2001), the ability to cope with life difficulties (Hill \& Pargament, 2003), and lower intake of alcoholic beverages amongst middle adults (Bazargan, Sherkat, \& Bazargan, 2004) as well as older adults (Krause, 1991). A study evaluating church attendance documented exercise and physical activities at two time points (1965 and 1994). Regular attendees (at baseline) were more likely to exercise regularly 30 years later (Strawbridge, Shema, Cohen, \& Kaplan, 2001).

Numerous studies have shown a negative association between religiousness and number of sexual partners and frequency of sexual encounters (Koenig, McCullough, \& Larson 2001; Paul, Fitzjohn, Eberhart-Phillips, Herbison, \& Dickson, 2000; Poulson, Eppler, Satterwhite, Wuensch, \& Bass, 1998; Thorton \& Camburn, 1989). Religion effectively serves as a buffer for risk-behavior amongst adolescents and emerging adults. Studies have also highlighted an association between religiosity and academic achievement in elementary and middle school children (Milevsky \& Levitt, 2004; Schottenbauer, Spernak, \& Hellstrom, 2007), as well as with Black and Hispanic high school students (Jeynes, 2003), despite unfounded assertions that the religious demographic is less academically adept than their non-religious counterparts (Decter, 1995; Olasky, 1988). 


\section{Religion and Marital Satisfaction}

Religiosity is also a predictor of marital and relationship satisfaction.

Relationship satisfaction and marital stability have consistently been associated with religious practice and beliefs (Call \& Heaton, 1997). For example, in a national survey of 4,587 married couples, results showed that when spouses regularly attended church together, they had the lowest risk of divorce among all married groups (Call \& Heaton, 1997). Indeed, religious involvement is a consistent predictor of long-term marriage (Kaslow \& Robison, 1996; Robinson \& Blanton, 1993).

Other studies have also found that marital satisfaction is positively correlated with religious involvement (Christiano, 2000; Lehrer, 2004; Wilcox, 2004). In general, studies have found that religious involvement is an important predictor of marital satisfaction, commitment, happiness, and adjustment (Hansen, 1992; Robinson, 1994). Many studies have included participants largely from Catholic and Protestant groups, but some investigations have also found a relationship between religious practices and marital satisfaction among religious Jews (Kaufman, 1991), Muslims, and Mormons (Dollahite \& Marks, 2005).

Although studies report both positive and negative attributes of marriage, marriage-advocates highlight the numerous benefits associated with marriage, as mentioned previously. Religion generally encourages marriage and discourages sexual relationships outside of wedlock. However, although studies often underscore the positive connection between religion and marriage, there are some studies that report the opposite. One such study showed religion to promote marital satisfaction when the couple was in good health, but religion seemed to diminish marital satisfaction when psychological 
problems were present (Sullivan, 2001). Nevertheless, the vast majority of literature has demonstrated positive relationships between marital satisfaction, religion, and overall wellbeing.

\section{Cross-Sex Experience}

As noted previously, cross-sex experience is thought to be a stepping-stone to the development of romantic relationship commitment. However, a common aspect in religious communities, particularly in Eastern religions, is gender segregation, often spanning across educational, social, and romantic experiences. Although many studies have addressed gender segregation in relation to education and occupation, few researchers have addressed the gender segregation phenomenon within a religious context. Following is a review of the rather limited literature on the effects of cross-sex experience.

\section{Gender Interaction and Segregation}

The phenomenon of voluntary sex segregation or gender-cleavage, described as the tendency to play, socialize, and interact with members of the same gender, has been reported in the literature as early as 1932 (Challman, 1932). Gender-cleavage is consistent cross-culturally (Belle, 1989; Gottman, 1986). It is acknowledged in the sociallearning model, based on divergent behavioral styles across genders (Maccoby, 1994). It is especially common in younger children and lessens considerably in early adulthood (Maccoby, 1998; Powlishta, 1995). In late adolescence and early adulthood, cross gender friendships and romantic relationships grow increasingly (Sullivan, 1953) and individuals engage in dyadic relationships, signifying the Intimacy versus Isolation stage in Erikson's (1968) theory. 
However, despite the normative progression to opposite sex interaction and dating cited in this review, such interaction is often precluded within cultural, ethnic, and religious contexts, little of which is reported in the literature. The majority of studies on gender segregation have focused on the educational setting. These studies are reviewed in this section, followed by a consideration of gender segregation and religion.

Gender segregation and education. Within pre-school education, voluntary gender-segregation is often found (Hoffman \& Powlishta, 2001); similarly, in middle and high school this phenomenon is found (Poulin \& Pederson, 2007), and it even extends into higher education (Barone, 2011), although gender segregation in college may be typically more indicative of occupational factors, such as choice of majors or activities dominated by males or females, than personal preferences.

Studies of gender segregation in educational settings have primarily addressed early childhood and elementary school education, looking at peer relationships and academic achievement, with a handful addressing the adolescent and adult populations. The No Child Left Behind Act (NCLB) of 1995 stimulated much interest and pressure to raise academic levels amongst public school students. As teachers and researchers evaluated factors related to learning, class gender composition (separate versus mixed gender) was also assessed.

Studies on the topic are largely inconclusive and offer varying results. Several studies report benefits of single-sex education (Rowe, 2000; Salomone, 2003). Other

studies list school culture (Riordan, 1999) and gender bias (Datnow, Hubbard, \& Woody, 2001) as greater indicators of academic success. 
Barton and Cohen (2004) report the social effects on boys and girls when separated by sex. Boys have shown stronger friendships and improved peer relations in same-gender classrooms, whereas girls in same-gender classrooms have shown more aggression than when in coeducational classrooms. The study did not follow up into later relationships with the opposite sex, nor did it evaluate long-term effects on peer-relations.

Gender segregation and religion. In some religious communities, limited intergender interaction is normative and institutionalized. Aside from separate gender schooling, social and sexual relationships are limited, largely to encourage matrimonial sanctity and to avoid premarital sexual relations. Research suggesting that romantic experiences are an important part of the adolescence experience (Connolly \& McIsaac, 2009) has primarily been focused on relationships in the West and has largely ignored divergent socio-cultural conceptions of romantic norms (Dion \& Dion, 1996), such as those of many Eastern cultures.

East/west differences. Recent cross-ethnic studies have reported less romantic involvement in non-Western cultures (Li, Connolly, Jiang, Pepler, \& Craig, 2010). Many cultures do not experience romance as a precursor to marriage. In Western cultures, selecting a mate is typically a matter of personal choice (Hamon \& Ingoldsby, 2003). Important factors in mate selection include love, companionship, and dating experience (Ingoldsby, 2003). By contrast, in many Eastern cultures, choosing a mate is a family and community endeavor (Hamon \& Ingoldsby, 2003). For the most part marriages are arranged by the families of the prospective couple. Family and societal norms carry more weight than individual opinion (Medora, 2003). Perhaps this is tied to the collectivistic and interdependent nature more common in Eastern culture than in the West. 
In Western cultures, peer groups contribute greatly to the romantic process and are viewed as a channel for romantic development (Connolly, Furman, \& Konarski, 2000; Dhariwal, Connolly, Paciello, \& Caprara, 2009). Spending time with oppositegender friends generally precedes romantic relationships and is viewed as a catalyst to romantic involvement (Connolly, et. al, 2004).

Non-Western youth tend to spend more time with same-sex peer groups and interact less with opposite-sex friends or those with more permissive attitudes (Feldman \& Rosenthal, 1990; Larson, et. al, 2002). Hence, they may not reach romantic relationships with the same cross-sex experience or at the same age as adolescents and young adults within Western communities.

In India, for example, adolescent romantic involvement is seldom condoned (International Institute for Population Sciences Mumbai \& Population Council New Delhi, 2010). One study (Abraham, 2002) interviewed teens and young adults in Mumbai, India and reported that family regulated the social interaction of youths, especially girls. Sex segregation was reported on varying levels depending on subcultures, ethnicities, religious affiliation, and caste status. Friendship and peer networks consisted mainly of same-sex members and premarital sexual activity was considered taboo.

Islamic cultures also often restrict cross-sex involvement. Many unmarried practicing Muslims do not engage in dating or romantic relationships and single men and women are prohibited from privately socializing or interacting (Rashidi \& Rajaram, 2001). Sexual activity is expected to remain within the framework of marriage and 
premarital sex is restricted (Rasool, 2000). Youths are actively protected from such activities through social norms enforced through peer influence and family oversight.

There is a trend, however, towards Western-style social and romantic cross-sex relationships. Increasingly, families are enrolling children in mixed-sex schools. Access to media may also play a role in this shift (Arnett, 2002; Larson Wilson, Brown, Furstenberg, \& Verma, 2002).

The initial study in this dissertation was focused on another population known to restrict pre-marital cross-sex interaction, the Orthodox Jewish community. Although there are a number of distinct denominations within this community, they can be broadly characterized as falling into one of two categories: Orthodox and Ultra-Orthodox. Jewish Orthodoxy and Ultra-Orthodoxy share more commonality than differences. With regards to Jewish law, ideology, and philosophy they are quite similar in comparison to other established subgroups within Judaism, such as Reform, Conservative, and Reconstructionist (Rosmarin, Pargament, \& Mahoney, 2009).

However, within the social context, the Orthodox and Ultra-Orthodox differ greatly. The Orthodox community tends to engage more in their social and ecological environs, sharing many typical experiences of the greater population, such as participating in neighborhood sport leagues, joining extra-curricular clubs, attending college, and dating. The Ultra-Orthodox community tends to be more insular and protective against outside influences. Social norms are more rigid and explicit (El-Or, 1994), effectively creating a distinct society in which the societal norms are markedly different from the surrounding culture. 
In what Heilman and Cohen (1989) dub "a contra-acculturative stance" toward the secular world, the Ultra-Orthodox community develops a protective barrier against external influence through internal language, private schools, and different foods. Watching television, which is a strong conveyer of social norms (Neuman, 1982), is frowned upon. Web-surfing or leisurely use of the Internet is increasingly discouraged. Recreational dating (not for marital purposes) is also highly unusual within this community. Given their insular model, there is a paradigm shift in terms of normative behavior and adjustment within this subgroup.

On the basis of literature regarding the general population, cross-sex interaction is an important component to experiencing and developing social and romantic relationships. Conversely, limiting such interaction may generate negative outcomes for relationship stability and marital satisfaction. However, the social context in which these experiences occur must be considered in achieving a general understanding of the literature. Mitigating factors, such as religious practice and support, may perhaps offset limited social and romantic experiences in religious communities.

Thus, as norms of socialization vary across cultures, consideration of cultural variation is necessary when addressing relationship satisfaction and adjustment. Many norms that are encouraged and accepted, and that have proven to be reliable predictors of adjustment within the general population, may not have the same benefit in cultures where such experiences are less normative. As Levitt (Levitt, 1991; Levitt et al., 1994) has proposed, relationship satisfaction and stability are likely to be related not only to prior relationship experience, but also to cultural norms governing relationships. 


\section{Research Aims}

This study is a two-part project. Study 1, included a unique population (UltraOrthodox Jews), which has clearly outlined restrictions of cross-sex experience (CSE) and effectively segregates genders before marriage. The goal of the study was to document the phenomenon of sex-segregation within religious and cultural contexts and to assess its relation to marital satisfaction and personal adjustment. The results provided a baseline for understanding divergent societal norms that are atypical in the general population, but may not be indicative of social or developmental problems within a specific cultural context.

Building on Study 1, Study 2 included a broader multi-ethnic sample of university students and extended the range of predictor and outcome measures to attempt to capture the phenomena leading to intimate relationship commitment and satisfaction for individuals from diverse cultural and religious backgrounds. Predictive measures in Study 2 included assessments of religious, ethnic/cultural, and familial norms regarding cross-sex interaction perceived to be espoused by the participants' social groups (Social Norms). Although there are differences in norms between Orthodox and Ultra-Orthodox Jewish denominations, normative expectations for cross-gender experience were not measured in Study 1. Thus, adding indices of cultural, religious, and familial norms in Study 2 afforded assessment of the extent to which social norms predict cross-sex experience and whether normative expectations also predict relationship and adjustment outcomes.

Study 2 also included measures of support received by participants through their cultural, religious and familial ties (Social Support), as the impact of social norms on 
cross-sex experience was expected to vary depending on the extent to which individuals received support from the groups holding those norms (a moderator effect). This prediction was based on the idea that high levels of support from family, ethnic/cultural, or religious groups would be more likely to promote adherence to norms regarding crosssex behavior

Both Study 1 and Study 2 assessed the amount of childhood and adolescent crosssex interaction experienced by participants (CSE). Also, outcome measures in each study included indices of relationship satisfaction and adjustment, although the satisfaction measures varied across the two studies.

Study 1 employed a marital satisfaction scale, as intimate, romantic relationships usually occur primarily within marriage for Ultra-Orthodox Jews, who tend to marry relatively early. A general relationship satisfaction measure was used in Study 2 which involved a more representative sample of young adult college students who are more likely engage in premarital romantic relationships and tend to marry later. Both studies used a standard scale indexing depression, anxiety, and stress to measure adjustment.

\section{Hypotheses:}

\section{Study 1}

Figures 1 is a path diagrams illustrating the hypothesized structural model linking predictors to outcomes that was tested in Study 1. Gender and length of marriage were included as exogenous demographic predictors in Study 1. Gender segregation is generally known to be stricter for girls than for boys in Ultra-Orthodox communities and was thus likely to be related to cross-sex-experience (CSE). Gender has also been associated with marital satisfaction in previous research (Mickelson, et. Al, 2006). 
(Women tend to be less satisfied with their marriages, compared to men). Length of marriage was included as a control measure, as numerous studies have shown a decline in marital satisfaction over time.

Cross-sex experience was hypothesized to predict marital satisfaction, as a major goal of the study was to determine whether this theoretical link would be found in this unique population. Relationship satisfaction was hypothesized to predict adjustment, in line with the results of research on more typical populations.

Specifically, the structural equation model designed for this study (Figure 1) included the following hypotheses:

H1. Gender will be related to CGE and to marital satisfaction, with males reporting more CGE, higher satisfaction, and less depression, anxiety and stress.

$\mathrm{H} 2$ : Years married will be inversely related to marital satisfaction, with satisfaction decreasing the longer participants are married.

H3: Religious orthodoxy will be inversely related cross-gender interaction, with greater orthodoxy predicting less CGE.

H4: Cross-gender experience will predict marital satisfaction.

H5: Marital satisfaction will be related to adjustment, with higher levels of satisfaction predicting lower levels of depression, anxiety, and stress.

\section{Study 2}

Figure 3 is a path diagrams illustrating the hypothesized structural model linking predictors to outcomes that was tested in Study 2. Predictive measures include (a) indices of familial, ethnic, and religious norms regarding cross-sex experience held by the groups to which participants belong (CSE Norms), (b) measures of social support 
received by participants from their families, and ethnic and religious groups (Social Support), and (c) the actual amount of cross-sex experience reported by participants (CSE), as for Study 1. Outcome indices include the relationship satisfaction measure and the adjustment measure from Study 1. An interaction term was included in the model to test whether the relation of CSE norms to CSE was moderated by social support.

The structural equation model designed for this study (Figure 3) includes the following specific hypotheses:

H1: CSE norms will predict CSE.

H2: Social support will moderate the relationship between CSE norms and CSE.

H3. CSE will predict relationship satisfaction.

H4: Relationship satisfaction will predict adjustment.

H5: Support will have direct effects on adjustment, independent of norms and relationship satisfaction. 


\section{METHODOLOGY}

\section{Study 1}

\section{Participants}

The sample included 213 females and 37 males with an average age of 28.64 years $(\mathrm{SD}=6.10)$ and 15.04 years of education $(\mathrm{SD}=2.31)$. All participants identified as religious and Jewish, with 162 identifying with an Ultra-Orthodox denomination and 88 identifying with an Orthodox denomination.

\section{Procedures}

Data collected in 2009 as part of a larger study were used in this secondary data analysis. In total, 250 married Jewish participants were recruited through flyers on university bulletin boards and online social networking sites. Participants responded to a series of online questionnaires that included an informed consent form. Participants remained anonymous throughout the study. A ten-dollar gift card was awarded to those who completed the survey.

\section{Measures}

The measures included two that are widely used to assess psychological adjustment and marital satisfaction, the Depression Anxiety Stress Scales (DASS-21, Lovibond \& Lovibond, 1995) and the Dyadic Adjustment Scale (DAS. Spanier, G. B., 1976). Also included were measures of gender segregation and experience, including the Cross-sex Experience scale (CSE, see Appendix) designed to assess cross-sex experience. Each of the measures are described below. 
Demographic Measures. Demographic measures included in the survey were participant gender, number of years married, and religious identification, classified as Orthodox or Ultra-Orthodox.

Cross-sex Experience scale (CSE). No standardized scale quantifying gender interaction could be accessed; therefore, the CSE was devised (Tamir \& Sacks, manuscript in preparation). The CSE (see appendix) is an 18-item self-report measure of an individual's interaction with members of the opposite gender during childhood and adolescence. Interactions in four separate domains were assessed: educational, family, social, and dating. The CSE includes items such as, 'As an adolescent, I had friends of the opposite gender'; 'I used email or social networking sites to interact with people of the opposite gender'; 'I spent vacations together with members of my extended family of the opposite gender'. Responses were rated on a five point Likert scale ranging from "Never" to "Very frequently".

Additional questions assessed the type of educational instruction received (samegender or mixed-gender) and social limitations on inter-gender interaction. For example, participants were asked 'How many siblings do you have of the opposite gender' and 'Have you participated in groups or clubs with members from the opposite gender'. The CSE total score ranges from 0 to 95 , with higher scores indicating higher levels of premarital inter-gender interaction. Cronbach's alpha for the study sample was .91, demonstrating high internal consistency.

Marital Satisfaction. The Dyadic Adjustment Scale (DAS, Spanier, 1976) was used to assess marital satisfaction. The 37-item scale included inquiries of the level of agreement between marital partners in matters of 'Handling finances', Matters of 
recreation', Philosophy of life', and 'Career decisions' using a 6-point Likert scale ranging from "Always agree" to "Always disagree". A reverse scoring technique was implemented resulting in higher scores signifying higher satisfaction. Alpha for the study sample was .87.

Psychological Adjustment. Psychological adjustment was indexed with the Depression Anxiety Stress Scales (DASS-21) (Lovibond \& Lovibond, 1995). Participants reported on incidences occurring up to 3 months prior to completing the survey. Sample items include 'I tended to over-react in situations'; I felt downhearted and blue'; I felt that life was meaningless'. Items are rated on a 4-point Likert scale: $0=$ Did not apply to me at all, $1=$ Applied to me to some degree, or some of the time, $2=$ Applied to me to a considerable degree, or a good part of the time, $3=$ Applied to me very much, or most of the time. Higher scores signify higher levels of depression, anxiety and/or stress. Thus, lower scores indicate greater well-being. Internal consistency reliability (Alpha) for the study sample was .90 .

\section{Study 2}

\section{Participants}

Of 1,709 participants recruited for the study, 1,553 provided sufficiently complete responses to an online survey and were included in the analyses for the purpose of this study. They were all college students at Florida International University (FIU) and were recruited via SONA Systems, the Psychology Department's online system for recruiting student participants. The FIU student body is a diverse and multiethnic population making it a good fit for this study. 
Of these participants $1,187(76 \%)$ were female and 366 were male $(24 \%)$. For sexual orientation $92 \%$ identified as heterosexual. For ethnic identity $69 \%$ of participants identified as Hispanic, 13\% identified as Black (5.2\% African American, 4.5\% Caribbean, 3.3 Haitian), 11\% identified as European American, 4\% identified as Asian American, and 3\% identified as Other. About 69\% of participants were born in the US and $31 \%$ were born in other countries. With regards to parents of participants $75 \%$ of mothers and $76 \%$ of fathers were born in other countries. Immigrants from Cuba were the largest group of immigrants, with $7 \%$ of participants, $22 \%$ of mothers, and $25 \%$ of fathers born in Cuba. The diversity of this sample can be seen in Table 1.

\section{Procedures}

The Study 2 survey was posted on Qualtrics, the university's online survey system. The survey was completely anonymous with no ability to link the information submitted to the students name, identification number, or email address. Students received extra credit for completing the survey.

\section{Measures}

Demographic measures. Demographic measures included participant age, gender, gender identification/orientation, ethnic/cultural background (racial/ethnic group with which the participant identifies, country of origin, parents' countries of origin), and religious group/background (Catholic, Jewish, Muslim, Protestant etc.).

Cross-sex experience (CSE). Cross-sex experience was assessed with the index developed for Study 1 (see Appendix). As described previously, the CSE scale is an 18 item retrospective self-report measure; interactions in four separate domains are assessed: educational, family, social, and dating. The CSE includes items such as; "As an 
adolescent, I had friends of the opposite gender" and "I used e-mail or social networking sites to interact with people of the opposite gender". Responses are rated on a five point Likert-scale ranging from "Very frequently" to "Never." Cronbach's alpha for the previous sample was 0.91 , indicating good internal consistency of the measure. As an indication of being well-positioned for more extensive psychometric testing, the measure distinguished the experience of the Study 1 Orthodox and Ultra-Orthodox groups known to diverge in beliefs and practices regarding cross-sex interaction. Cronbach's alpha for the study sample was .82, demonstrating high internal consistency.

Religious, Ethnic/Cultural, and Familial CSE Norms. Social norms regarding cross-sex interaction held by participants' religious, ethnic/cultural, and family groups were measured through indices developed for this study, following on the previously developed CSE measure. Participants indicated on a 5-point scale the extent to which each normative statement is "completely true" to "not at all true" for their religious, cultural, or family group. Sample items are, "Adolescents are allowed to date members of the opposite gender of their choosing" and "Young people are expected to live with their parents until marriage". Cronbach's alpha for the study sample was .85 demonstrating high internal consistency.

Social support. The survey included measures of social support from family, ethnic/cultural, and religious groups. However, as only a third of the respondents completed items related to religious support, the religious support measure was not used in the analyses. Support was measured with 7 4-point scale items from the National Survey of American Life conducted by the Institute for Social Research at the University of Michigan (Jackson, Torres, Caldwell, Neighbors, Nesse, Taylor, Trierweiler, \& 
Williams, 2004). Examples are, "How close do you feel to other people in your ethnic/cultural group? ("Very close" to Not close at all"), and "How often do other people in your ethnic/cultural group express interest and concern in your well-being? ("Very often" to "Never"). Cronbach's alpha for the study sample was .75.

Relationship Satisfaction. Relationship satisfaction was measured with the 7-item Relationship Assessment Scale (RAS. Hendrick, 1988). It includes items such as; 'How well does your partner meet your needs' and 'How many problems are there in your relationship", measured on a 5 -point Likert-scale, with $1=$ Low and $5=$ High. The RAS taps domains of satisfaction similar to those assessed in the DAS marital satisfaction scale employed in Study 1. Cronbach's alpha for the study sample was .76.

Psychological Adjustment. As in Study 1, psychological adjustment was indexed using the Depression Anxiety Stress Scales (DASS-21) (Lovibond \& Lovibond, 1995). Participants reported on incidences occurring up to 3 months prior to completing the survey. Sample items include 'I tended to over-react in situations'; I felt downhearted and blue'; I felt that life was meaningless'. Items are rated on 4-point Likert scale: $0=$ Did not apply to me at all, $1=$ applied to me to some degree, or some of the time, $2=$ Applied to me to a considerable degree, or a good part of the time, $3=$ Applied to me very much, or most of the time. Higher scores signify higher levels of depression, anxiety and/or stress. Thus, lower scores indicate greater well-being. Cronbach's alpha for the study sample was .87 , demonstrating high internal consistency. 


\section{IV.RESULTS}

\section{Overview of Analyses}

Analyses for both studies included preliminary descriptive analyses and assessments of the distributional characteristics of the data. To examine the relationships among variables, Structural Equation Modeling (SEM) analyses were performed.

Structural Equation Modeling is an integration of a measurement model and pathanalytic model. SEM is an analytic technique that explores direct and indirect relationships between one or more independent and dependent variables. The approach is confirmatory in nature and specifies causal processes with a series of regression equations that are tested to fit the observed processes (Bryne, 2001). As outlined by Jaccard (2010), all path coefficients in the model are simultaneously examined and tested for statistical significance. Structural Equation Modeling evaluates global model fit, independently from significant path coefficients. Thus, SEM is useful in examining multidimensional relationships, providing analysis of concurrent tests of each relationship. Structural Equation Modeling's ability to examine multiple regression and path analyses while concurrently considering unique components of variance and measurement error (Hoyle Panter, 1995; Kline, 1998) makes SEM a powerful statistical technique.

Global fit indices were used in an effort to assess the fit of the model to the data, as suggested by Bollen and Long (1993). Absolute fit, indices of relative fit, and indices of fit with a penalty function for lack of parsimony were examined. The chi-square and its probability factor ( $p$-value) were evaluated, with a higher $p$-value indicating a closer fit between the hypothesized model and the model fit (Bryne, 2001). Another global fit 
index that was examined was the comparative fit index (CFI). (CFI compares the hypothesized model with the independence model). A CFI of 0.95 or greater indicates a good model fit. Accounting for the error of approximation in the population, the root mean square approximation (RMSEA) was utilized. A RMSEA of less than 0.08 indicates a good model fit. Finally, more focused tests of model fit were examined. The standardized residual covariances (between -2.00 and 2.00) and modification indices (less than 4) were analyzed (Jaccard, 2010).

The model fits of the current studies were evaluated using AMOS 18.0 software (Arbuckle, 2006). The models were good fits for the data in each study. Study 1 and Study 2 final models can be found in Figures 2 and 4 respectively.

\section{Study 1}

Descriptive Analyses

The means and standard deviations for the Study 1 measures can be found in Table 2. Intercorrelations (Pearson correlation coefficients) of the measures are included in Table 3. CSE was related significantly to Gender; males had more experience than females. CSE was also related significantly to Denomination; the Orthodox group had more experience than the Ultra-Orthodox group. Years Married was inversely related to Marital Satisfaction and Marital Satisfaction was related significantly to scores on the Depression, Anxiety, Stress Scale.

\section{Structural Model Analyses}

The structural model developed for Study 1 can be seen in Figure 1. All statistical analyses were performed with SPSS 18.0 or AMOS 18.0. Structural equation modeling was utilized in Study 1 to examine the effects of years married and gender on marital 
satisfaction, denomination and gender on CSE, CSE on marital satisfaction, and marital satisfaction on adjustment.

Preliminary Analyses. There were no missing data. Outlier analyses were undertaken prior to all major analyses. Multivariate outliers were identified by examining leverage indices for each individual, defining an outlier as a leverage score four times greater than the mean leverage (Wilcox, 1997, 1999, 2003). No outliers were found.

Multivariate normality was evaluated using Mardia's test for multivariate normality. In addition, univariate indices of skewness and kurtosis were examined to determine if the absolute value of any of these indices was greater than 2.0. Three variables had kurtosis values of 2.0 and greater. These were Years Married (3.45), Marital Satisfaction (3.88) and Depression (2.50). Multivariate normality as measured by Mardia's test was significant with a C.R. value $>1.96$. These coefficients are negatively affected by high kurtosis and low sample numbers. Because of the abnormal distributions, all of the modeling was performed twice, first using Maximum Likelihood Estimators (MLR) and the second using bootstrapping. The two results were found to be similar and consequently only the conventional results are reported here.

Notes for Model Fit and Model Fit Statistics. Following the recommendations of Bollen and Long (1993), a variety of global fit indices were used. The overall chi-square test of model fit was not statistically significant $\left(\chi^{2}(15)=23.38, p>.05\right)$. The CFI was .94 . RMSEA was .047. The Standardized Root Mean Square Residual (SRMR) was .05. All of these indices point to a good model fit. Inspection of the residuals and the 
modification indices revealed no significant points of ill fit. Table 4 presents the $95 \%$ confidence intervals for the unstandardized path coefficients in the structural model.

Standardized and Unstandardized Path Coefficients. Figure 2 presents the standardized and unstandardized (in parentheses) path coffeicients yielded by the analysis. As anticipated, length of marriage was related significantly $(p<.001)$ to marital satisfaction. For every one year increase in years married, there was a .79 unit decrease in marital satisfaction. Denomination orthodoxy was also related significantly $(p<.001)$ to cross-sex experience. For every one unit increase in denomination (Orthodox to UltraOrthodox), there was a 19.87 unit decrease in cross-sex experience. Marital satisfaction was related significantly $(p<.001)$ to adjustment. For every one unit increase in marital satisfaction, there was a .34 unit decrease in the Depression, Anxiety, and Stress scale. Links between gender and cross-sex experience $(p<.05)$ were related significantly with men reporting a .14 unit increase in experience. Gender and cross-sex experience were not related significantly to marital satisfaction.

\section{Study 2}

\section{Descriptive Statistics}

Means and standard deviations for the measures used in Study 2 can be found in Table 5. Intercorrelations of the measures can be found in Table 6. The Pearson correlation coefficients indicated significant relationships between variables. Family norms related to cultural support $(\mathrm{p}<.05)$ and family support, CSE, relationship satisfaction, and adjustment $(\mathrm{p}<.001)$. Cultural norms was highly correlated with family norms, family support, CSE $(\mathrm{p}<.001)$ as well as with CSE and adjustment $(\mathrm{p}<.01)$, and relationship satisfaction $(\mathrm{p}<.05)$. Religious norms were correlated with cultural norms, 
family norms, and CSE $(\mathrm{p}<.001)$, as well as family support $(\mathrm{p}<.01)$. Family support was highly correlated with CSE, relationship satisfaction, and adjustment $(\mathrm{p}<.001)$. Cultural support was related to family support, CSE, relationship satisfaction, and adjustment. Cross-sex experience was related to relationship satisfaction and adjustment and lastly, relationship satisfaction was related to adjustment (all at a $\mathrm{p}<.001$ level

\section{Structural Model Analyses}

In the Study 2 model (Figure 4), religious norms, cultural norms, and family norms, family support, and cultural support were all exogenous variables. As noted previously, religious support was not included in the model analyses because two-thirds of the respondents did not complete the religious support scale. Endogenous variables included cross-sex experience, relationship satisfaction, and adjustment. The fit of the model in Figure 4 was evaluated using AMOS 18.0 (Arbuckle, 2006).

Preliminary Analysis. Aside from the religious support measure, there were no missing data. Outlier analyses were undertaken prior to all major analyses. Multivariate outliers were identified by examining leverage indices for each individual, defining an outlier as a leverage score four times greater than the mean leverage (Wilcox, 1997, 1999, 2003). No outliers were found.

Structural equation modeling requires data employed in the analyses to be normally distributed (Byrne, 2001). Multivariate normality was evaluated using Mardia's test. The data were found to have a multivariate normal distribution. Additionally, Lei and Lomax (2005) ascribe univariate normality as having absolute skewness and kurtosis values of 2.3 and lower. Univariate indices of skewness and kurtosis revealed no skewness or kurtosis above an absolute value of 1, indicating normal distribution. 
Notes for model fit and model fit statistics. The null hypothesis postulated that the specification of the model was valid and the Chi-Square test evaluated the likelihood that this statement was true. In the current study, the overall chi square test of model fit was not statistically significant $\left(\chi^{2}(11)=13.7, p=0.253\right)$. RMSEA was .012 . The $p$ value for the test of close fit was 1.00 . The CFI was .999. The GFI was .999. The standardized root mean square residual was .0113. Overall, the indices point towards good model fit. Inspection of the residuals and modification indices revealed no significant points of illfit in the model.

Figure 4 presents the standardized and unstandardized (in parentheses) path coefficients. The residual variances for the endogenous variables are presented only in standardized form. Table 7 presents the $95 \%$ confidence intervals for the unstandardized path coefficients in the structural model. The variables in the model accounted for approximately $11 \%$ of the variance in adjustment, $4 \%$ of the variance in relationship satisfaction, and $9 \%$ of the variance in cross-sex experience.

Standardized and Unstandardized Path Coefficients. Figure 4 includes the standardized and unstandardized path coefficients for the model. All of the path coefficients were statistically significant. For every one unit increase in religious CSE norms there was a $0.09(0.09)$ unit increase in CSE, for every one unit increase in family CSE norms there was a $0.05(0.04)$ unit increase in CSE and a 0.05(0.04) increase in relationship satisfaction. For every one unit increase in cultural CSE norms there was a 0.07(0.18) unit decrease in depression, anxiety, and stress. For every one unit increase in family support, CSE increased 0.15 (.37), relationship satisfaction increased 0.04 (.09), and depression, anxiety, and stress decreased $0.25(-1.6)$. For every one unit increase in 
cultural support, CSE increased $0.19(.45)$, relationship satisfaction increased $0.08(.16)$, and depression, anxiety, and stress decreased 0.05 (-.32). Family norms also moderated the relationship between family support and CSE (see Figure 4). CSE predicted relationship satisfaction, for every one unit increase in CSE there was a 0.12(.09) unit increase in relationship satisfaction. For every one unit increase in relationship satisfaction there was a $0.12(.39)$ decrease in depression, anxiety, and stress. 


\section{DISCUSSION}

\section{Study 1}

The goal of Study 1 was to assess the generalizability and salience of factors that contribute to marital satisfaction and adjustment in the general U. S. population to a divergent population, the Orthodox Jewish community. It was essential to consider cultural context when assessing factors related to marital satisfaction and adjustment, as norms of socialization vary across cultures, and predictors of satisfaction and adjustment within the general population may not demonstrate the same benefit in cultures where such predictive experiences are less normative.

As had been found previously in the general population, marital satisfaction predicted lower rates of depression, anxiety and stress in this sample of Orthodox Jews, suggesting that marital relationships were as significant for this group as for the larger culture. The study also confirmed previous findings of an inverse relationship between marital satisfaction and years married. Vaillant and Vaillant (1993) reported similar results in their longitudinal study tracking marriages and divorces over the course of 40 years. Their findings indicated that over time marital satisfaction steadily declines for approximately 15 years before stabilizing for the subsequent 25 years. This decline may be attributed to the optimistic nature of newlyweds or general difficulties encountered throughout adult life that are taxing on well-being and marriage (Huston, Caughlin, Houts, Smith, \& George, 2001).

Also paralleling general population findings, the link between gender and marital satisfaction approached significance, and would likely have been significant had more males been included in the sample. As predicted, there was a clear distinction between 
the Orthodox and Ultra-Orthodox groups in relation to cross-sex experience. Orthodox participants reported more cross-sex social interactions, friendships, and romantic relationships than Ultra-Orthodox participants. This finding provided some external validation for the Cross-sex Experience measure developed for the research on which this study was based.

However, cross-sex experience was not related significantly to marital satisfaction in this study. As described previously, with regard to prior research on cross-sex experience, Meier and Allen (2009) succinctly described the pattern of development in typical populations. Romantic experience in adolescence is considered to be an important component of relationship building and the development of lasting relationships in adulthood. Adolescents who do not benefit from these experiences often report difficulty forming relationships later in life. However these results must be addressed in the context of societal norms. Cross-sex experiences and particularly dating relationships in adolescence are normative within the general United States population, but would be considered a violation of the norms generally adhered to by Orthodox Jews.

These results were consistent with the model of relationship satisfaction proposed by Levitt (1991, Levitt et al., 1994) suggesting that relationship satisfaction may be governed by cultural norms as well as prior experience. While the absence of a link between cross-sex experience and marital satisfaction is a null finding, there are some factors that support the conclusion that cross-sex experience was, in fact, not associated with marital outcomes for this population. This presumption is bolstered by the fact that other associations established in research with the population at large did replicate in the current study, including the links between length of marriage and marital satisfaction, 
between gender and marital satisfaction, and between marital satisfaction and adjustment. Also, given the normative nature of sex separation for the religious participants interviewed in this study, the lack of a connection between cross-sex experience and marital satisfaction is consistent with the theoretical view that social norms factor into relationship satisfaction.

There is an extensive body of research indicating a relationship between religiosity and marital satisfaction. There are also many studies that link romantic experiences to lasting relationships in adulthood. Given that some religious communities promote and support marital stability, yet limit premarital cross-sex experience, cultural norms and social support in these communities may offset the lack of relationship experience as young adults transition into marriage.

In sum, Study 1 was a first step toward uncovering the effects of societal, cultural, and religious norms regarding cross-sex experience on relationship outcomes. The findings are consistent with the view that culture and society impact the trajectory of an individual's development. It was apparent from these findings that further research was needed to focus on identifying specific cultural norms and social supports that impact marital outcomes. Additionally, there was a need to expand the study to relationship satisfaction outside of marriage, in light of the deferment of marriage that has become increasingly common in young adults. In general, further research was necessary to address variables that impact adjustment across unique cultures and to investigate patterns of social support that encourage positive development cross-culturally. Study 2 was designed to address these issues 


\section{Study 2}

Study 2 was designed to address and expand the findings of Study 1 . Whereas Study 1 focused on a unique population known to restrict cross-sex experience prior to marriage, Study 2 employed a much broader multi-cultural sample of young adult college students. In Study 1, contrary to existing theory regarding the development of romantic relationships, cross-sex experience was unrelated to marital satisfaction. A primary goal of Study 2 was to determine whether the widely theorized linkage of cross-sex friendships and dating experiences to the development of satisfying romantic relationships in early adulthood could be found in a more representative sample of young adults.

The results of Study 1 also suggested that differential normative expectations were responsible for differences in cross-sex experience between the Orthodox and UltraOrthodox Jews in the study sample. Thus, another major goal of Study 2 was to assess directly the relation of religious, cultural, and family norms to cross-sex experience and relationship outcomes. Study 2 also included measures of social support, as the extent to which young adults adhere to normative expectations is likely to covary with the support provided by the groups endorsing these norms.

Finally, Study 1 was limited to married individuals, as romantic relationships outside of marriage are rare in Ultra-Orthodox Jewish communities. However, young adults in the U.S. today generally do develop romantic relationships outside of marriage. Thus, Study 2 assessed general romantic relationship satisfaction.

The test of the structural model proposed for Study 2 (Figure 4) confirmed several hypotheses. CSE norms had a direct effect on CSE, validating a theoretical construct 
upon which this study was based, that social and romantic behavior is influenced by socio-cultural norms. Family and religious norms relating to CSE predicted the extent to which participants engaged in cross-sex experiences. These findings are aligned with views regarding the development of romantic relationships outlined in the literature (e.g. Levitt, 1991; Levitt, Coffman, Guacci-Franco, \& Loveless, 1994; Sullivan, 1953). Specifically it has been proposed that the development of social relationships follows a progression building on attachment in infancy, expanding to interaction with a larger social network in childhood and adolescence, and leading to romantic experiences in early adulthood. Along these lines, increased cross-sex experience indicates social aptitude and likelihood in forming better relationships. This is further illustrated by the significant relationship between CSE and relationship satisfaction, consistent with the premises upon which the dominant attachment and interpersonal theories are based (e.g. Sullivan, 1953).

Based on the literature and theoretical groundwork in cultural research, social support was expected to moderate the relationship between CSE norms and CSE. Confirming the hypothesis to some extent, the extent to which family norms predicted CSE was moderated by family support. Family norms were especially predictive of crosssex experience in the context of high family support. Thus, family support in particular interacted with CSE norms regarding socializing, dating, and sexual behavior to predict norm adherence, as reflected in reported actual cross-sex behavior.

Family and cultural support also had a significant direct impact on CSE, which can be understood as family and cultural support leading to social competence, increased interactions, and positive relationships, consistent with theories of social networks and 
relationship formation (Bronfrenbrenner, 1978; Levitt, 1991; Vygotsky, 1978). Family CSE norms also impacted relationship satisfaction directly, along with the apparent progression of permissive family norms regarding cross-sex experiences leading to increased cross-sex experiences, and subsequently increased relationship satisfaction. Cultural support also predicted relationship satisfaction directly, although, interestingly, family support did not. This can perhaps be attributed to the nature of romantic relationships in young adulthood as being individualistic, between two partners and separate from family experiences (Hofstede, 2001), whereas socio-cultural support from peers and others may be more directly related to the nature of romantic relationships. Taken together, these findings suggest that families are especially significant conveyors of normative expectations and support, but that culture also plays a meaningful role. As hypothesized, relationship quality predicted adjustment. This finding is aligned with the body of literature indicating that relationship satisfaction contributes to wellbeing (e.g. Bouchey, 2007) and reduces adjustment difficulties (Rusbult \& Van Lange, 1996), such as depression, anxiety, and stress.

It is interesting to note that cultural norms regarding cross-sex experience also had a direct relationship with adjustment. The more permissive the cultural CSE norms, the less depression, anxiety, and stress was reported. This finding may reflect the potential for disconnect, especially for young adults with strong ties to their cultures of origin, between the norms of their cultures and the norms of the U.S. peer culture that promote early dating and sexual experience. Thus, greater alignment of cultural norms to the relatively permissive CSE norms generally held by U.S. youth could be expected to predict more positive adjustment. 
Not surprisingly, family and cultural support also predicted adjustment, with greater support predicting less depression, anxiety, and stress. These findings are consistent with the large body of literature indicating that social support fosters positive adjustment.

\section{General Discussion}

The findings in each study were discussed in the preceding sections. The following discussion addresses the overall findings of the research, the progressive nature in which both studies were designed, and their contribution to the current body of social and romantic relationship literature.

Measuring CSE and socio-cultural norms in study 1, provided a framework for understanding paths to developing romantic relationships and overall adjustment, outside of the normative progression of social and romantic relationships outlined in social and interpersonal theories, moving beyond the typical nature of cross-sex experiences; i.e. voluntary sex-segregation in childhood, increased cross-sex experience as groups in early adolescence, and progressively more intimate relationships into early adulthood (Sullivan, 1953). Based on these established theories, inability to interact socially or romantically with the opposite sex would indicate maladaptive social ability. Indeed within the context of dominant U.S. social norms, lack of CSE would indicate an inability to develop and maintain relationships in adolescence and young adulthood that would be of concern. However, within cultures where the CSE norms are different and the expectations for dating and sexual behavior are more restrictive, cross-sex experience and its link to relationship and adjustment outcomes could be expected to differ from the normative progressive nature of CSE in a typical US population. 
Study 1 focused on a unique population (ultra-Orthodox Jews) that maintains sexsegregation in social and romantic settings. Dating and romantic experiences are limited to marriage-oriented adults. Within such a population, the common measuring tool of social and romantic ability is ineffective. Within this group, lack of CSE is part of membership and acceptance; it demonstrates cohesion between individual and culture, which is generally associated with positive adjustment. Yet, based on the literature and theories of normative development, an entirely different conclusion could be drawn, that lack of CSE would affect marital satisfaction.

Thus a primary purpose of Study I was to underscore one of various paths leading to relationship satisfaction and adjustment that have been missing from the literature. In fact, CSE in this group was not related to marital satisfaction. These findings provided a base upon which to broaden the scope of factors contributing to relationship success and to move away from the, perhaps over-simplified and general assumptions regarding relationship formation and success.

Acknowledging divergent paths to relationship satisfaction and adjustment, Study 2 included variables of socio-cultural CSE norms and support. It included a larger sample that was more representative of young adult college students. In doing so, it was able to yield data in support of the interpersonal and social/romantic theories espoused in the literature, in line with the normative sequence outlined in these theories, namely more permissive CSE norms predicted more actual CSE, and more CSE predicted greater relationship satisfaction.

The findings are important for a number of reasons: Firstly, they serve to validate the CSE measure which was created for Study 1 (and used in both studies). The 
development of this measure will aid further study on cross-sex experience, as no such measure has been available in the past.

The findings of this research also deepen our understanding of culture-specific differences that contribute to relationship outcomes. The results obtained with a broad sample of college students in Study 2 were consistent with the normative progression to romantic relationships outlined in the literature, but provided an entirely different narrative when compared to Study 1 . The Study 1 results suggest that the normative linkage of cross-sex experience to intimate relationship formation and satisfaction may not hold for populations with high in-group support and norms that restrict such experience. The expanded results of Study 2 provide direct confirmation of the relation

of family, cultural, and religious norms regarding CSE to actual CSE and demonstrate that family and cultural support are predictive of CSE, relationship satisfaction, and adjustment. In general, these findings demonstrate the complex involvement of many factors that contribute to interpersonal relationships and adjustment.

\section{Limitations}

Limitations of the research are described in this section. Some limitations were unique to each study and some were common across studies.

Study 1. In Study 1, first there were limitations to the sample. Of 250 participants, only $38(<15 \%)$ were male, limiting the ability to evaluate gender differences in cross-sex experience and marital satisfaction. Gender differences were of particular interest in Study 1 because of the gender segregation inherent in the population.

Also, participants were identified as either Orthodox or Ultra-Orthodox. Given the homogenous nature of these two groups, in comparison to the general population, a 
non-Orthodox control group would have created a more heterogeneous sample that could offer more insight into the effects of variations in religiosity on romantic relationship formation. Additionally, a broader understanding of the participants' religious beliefs and practices may have added insight into the relationship between denomination and belief systems.

It should be noted that the absence of a link between cross-gender experience and marital satisfaction in Study 1 is a null finding, with attendant difficulties in assessing its meaning. However, there are some factors that support the conclusion that cross-gender experience is, in fact, not associated with marital outcomes for this population. The sample size of 250 in this study was substantial and certainly sufficient to detect an effect if it existed within this population. Furthermore other associations established in research with the population at large did replicate in the current study, including the links between length of marriage and marital satisfaction and between marital satisfaction and adjustment. Finally, given the normative nature of gender separation for the religious population queried in this study, the absence of an association between cross-gender experience and marital satisfaction is consistent with the theoretical view that social norms factor into relationship satisfaction

Study 2. The sample used for Study 2 was a convenience sample. Although the inclusion of a multi-ethnic population is a strength of the study, all of the participants were college students, somewhat limiting the generalizability of the study. (And it might be argued that the local student population is atypical because it is so multi-cultural; however, the U.S. population in general is becoming increasingly multicultural). Also, most participants ( $>80 \%)$, were under 25 years old; this certainly sheds light on patterns 
of social networks among young/emerging adults, but the results cannot be extended to middle or older adults who may place different value on socio-cultural norms, support, and CSE.

Another limitation is that the effects, while significant, were generally modest. The study was designed to evaluate the progression of CSE in childhood and adulthood as precursors to adult romantic relationships, but there are likely to be other variables that contribute to disregarding norms or embracing alternate norms. For example, 1,026 participants reported being raised Catholic, and subject to those religious norms, yet only 246 reported maintaining that religious identity in adulthood. So despite exposure to specific CSE norms as children or adolescents, as adults participants do not necessarily identify with these norms.

Furthermore, the participants are part of a larger culture, namely U.S. college students, which may supersede the influence and importance of familial, religious, or ethnic norms, especially regarding dating and sexual behavior. Another contributor may be the difference between stated or ideal norms and actual behaviors and norms. For example adolescent sexual activity may be against stated religious norms but not quite against the actual norms of that particular demographic.

General Limitations. Some limitations were common to both studies. First, all of the data was collected online. Although this method of data acquisition has become increasingly common, and the findings are consistent with a large body of literature, there is still some debate regarding the reliability and accuracy of online surveys and therefore deserves mention. Second, it is important to note that, as with any correlational methodology, a limitation of using structural equation modeling is establishing the 
direction of effects. Although the results demonstrate good model fit consistent with the theoretical underpinnings of the study, the extent to which the modeled relationships among the variables replicate the veridical covariance of variables in nature remains uncertain. Third, due to the paucity of literature on cross-sex experience a measure was created, limiting its validity, however based on these two samples the measure is well positioned for more extensive psychometric testing.

Finally, all of the data were based on self-reported measures; consequently results are potentially subject to common method bias. Although statistical analyses, such as Harman's one-factor test utilize exploratory factor analysis to diminish concern for common method bias, it remains a challenge with survey research (Podsakoff, et. al, 2003). It would be important for future research to obtain independent observations and reports.

\section{Conclusions}

A primary aim of this research was to assess the relation of cross-sex experience to relationship satisfaction and adjustment, in line with extant theories suggesting that cross-sex experience is important for the development of intimate relationships in young adulthood, while recognizing the potential importance of socio-social context. For the sample of Orthodox and Ultra-Orthodox Jews in Study 1, marital satisfaction was associated with personal adjustment, as it is in more typical U.S. populations. However, cross-sex experience was not linked to relationship satisfaction or adjustment for this culturally divergent group. A plausible explanation for this outcome is that limits on premarital cross-sex experience are normative for this population, so that expectations regarding marital partners are based on factors other than prior experience with dating or 
other aspects of cross-sex interaction. High levels of support within this population may also contribute to individual endorsement of normative restrictions and a consequent disconnect between cross-sex experience and marital relationship expectations.

The findings of Study 1 suggested the need to expand the research to a broader and more diverse population including multiple races, ethnicities, and religions, which may be more representative of normative patterns in social and romantic developmental trajectories. Thus, Study 2 included a multicultural sample of university students. The range of predictor and outcome measures was also extended to attempt to capture the phenomena leading to intimate relationship commitment and satisfaction for individuals from diverse cultural and religious backgrounds. Variations in support from members within family and social networks were addressed. Associations of cultural, religious, and familial norms to cross-gender experience, relationship satisfaction, and adjustment were also addressed.

Study 2 effectively confirmed previous literature on relationship formation and broadened the understanding of relationship formation within socio-cultural contexts. It set out to measure CSE in a more normative young adult population and to evaluate theoretical constructs regarding the underpinnings of romantic relationships. The study results were consistent with the view that cross-sex experience is linked to intimate relationship satisfaction in young adults. The results further highlight the additional factors that contribute to interpersonal and romantic relationships, demonstrating the influence of family, ethnic, and religious norms and support in addition to the broader cultural norms that inform US-college students' engagement in social and romantic activities. 
This research generally challenges the simplistic theoretical understanding of human social and romantic interaction. Within a relationship-centric society, these studies provide deeper insight into social networks and the values, experiences, expectations, and culture individuals bring into a relationship.

The current research breaks new ground in developing measures of cross-sex experience and associated social norms, along with assessing directly the relation of social norms, in the context of social support, to cross-sex experience and relationship outcomes. However, as alluded to throughout this discussion, there are a number of other avenues that remain to be explored in future research, including the interrelation of cultural, religious, and family norms with potentially conflicting norms in the individuals' social settings (culture of origin norms versus college student norms, for example). Another important extension of the current research would be to study other unique populations varying in normative beliefs and restrictions regarding cross-sex interactions.

Finally, for the purpose of this study, classic markers such as dating, intimacy, sexual intercourse, and marriage were used to quantify romantic experiences. However, the landscape of romantic relationships has changed drastically over the past 50 years. Researchers are only beginning to uncover the changes in adolescent and young adult intimate activity. For example, youth are engaging in sexual activity at a younger age (Finer, 2007), young adults are marrying later (Smock \& Manning, 2004), and cohabiting more often (Smock, 2000). The repertoire of sexual activity amongst young adults has expanded far beyond conventional dating and marriage. Terms such as "friends with benefits" (FWBs, sex within the context of friendship, without expectations of future 
romantic involvement [McGinty, Knox, \& Zusman, 2007]), "hook-ups” (sex without emotional intimacy [Paul, McManus, \& Hayes, 2000], and "living apart together" (LAT, committed couples live apart [Strohm, Seltzer, Cochran, \& Mays, 2009]), are increasingly common among young adults (Jameson \& Ganong, 2010). The impact of these types of relationships on intimate and committed relationships has yet to be established in the literature. 


\section{REFERENCES}

Abraham, L. (2002). Bhai-Behen, True Love, Time Pass: Friendships and Sexual Partnerships among Youth in an Indian Metropolis. Culture, Health \& Sexuality, 4, 337-353

Ainsworth, M. S. (1989). Attachment beyond intimacy. American Psychologist, 44, 709-716.

Ainsworth, M. S., Blehar, M. C., Waters, E., \& Wall, S. (1978). Patterns of attachment: A Psychological study of the Strange Situation. Hillsdale, NJ: Erlbaum.

Akiyama, H., Antonucci, T.C., Takahashi, K., \& Langfahl, E. S. (2003). Negative interactions in close relationships across the lifespan. Journal of Gerontology: Psychological Sciences, 58B, 70-79

Antonucci, T. (1976). Attachment: A life-span concept. Human Development, 19(3), 135-142.

Antonucci, T.C. (1986): Measuring social support networks: Hierarchical mapping technique. Generations, 3, 10-12.

Antonucci, T. C., Birditt, K. S., \& Akiyama, H. (2009). Convoys of social relations: An interdisciplinary approach. (pp. 247-260) Springer Publishing Co, New York, NY.

Arbuckle, J. L. (2006). Amos (Version 18.0) [Computer program]. Chicago: SPSS.

Arnett, J. J. (2002). The psychology of globalization. American Psychologist, 57, 774783.

Arnett, J. J. (2000). Emerging adulthood: A theory of development from the late teens through the twenties. American Psychologist, 55, 469-80.

Baltes, P. B., Reese, H. and Lipsett, L. (1980). Lifespan developmental psychology, Annual Review of Psychology 31, 65-110.

Barone, C. (2011). Some things never change: Gender segregation in higher education across eight nations and three decades. Sociology of Education, 84, 157-176.

Bartholomew, K., \& Horowitz, L. (1991). Attachment styles among young adults: A test of a four-category model. Journal of Personality and Social Psychology, 61, 226244.

Bates, A. (1942). Parental role in courtship. Social Forces, 20, 482-486. 
Barton, B., \& Cohen, R. (2004). Classroom gender composition and children's peer relations. Child Study Journal, 34, 29-45.

Bazargan, S., Sherkat, D. E., \& Bazargan, M. (2004). Religion and alcohol use among African-American and Hispanic inner-city emergency care patients. Journal for the Scientific Study of Religion, 43, 419-428.

Belle, D. (1989). Gender differences in children's social networks and supports. In D. Belle (Ed.), Children's social networks and supports, 173-188. New York: Wiley.

Berman, W. H., \& Sperling, M. B. (1991). Parental attachment and emotional distress in the transition to college. Journal of Youth and Adolescence, 20, 427-440.

Billingsley, A. (1992). Climbing Jacob’s Ladder. New York: Simon and Schuster.

Blau, P. (1964). Exchange and power. New York: John Wiley and Sons.

Bollen, K. \& Long, S. (1993). Testing structural equation models. Newbury Park: Sage.

Bowlby, J. (1969/1997). Attachment and loss: Vol. 1 Attachment. London: Pimlico/Random House, UK.

Bradburn, N. M. (1969). The structure of psychological well-being Aldine, Oxford.

Bretherton, I., \& Munholland, K.A. (1999). Internal working models revisited. In J. Cassidy \& P.R. Shaver (Eds.), Handbook of attachment: Theory, research, and clinical applications (pp. 89-111). New York: Guilford Press.

Bronfenbrenner, U. (1979). The ecology of human development: Experiments in nature and design. Cambridge, MA: Harvard University Press.

Brown, B. Bradford. (1999). “'You're Going Out with Who?!': Peer Group Influences on Adolescent Romantic Relationships.” The development of romantic relationships in adolescence. (pp. 291-329). New York: Cambridge University Press.

Call, V.R.A. \& Heaton, T.B. (1997). Religious influence on marital stability, Journal for the Scientific Study of Religion 36, pp. 382-392.

Campbell, A., Converse, P.E. \& Rodgers, W.L. (1976). The quality of American life: Perceptions, evaluations, and satisfactions. New York: Russell Sage Foundation.

Campbell, W. K., Sedikides, C., \& Bosson, J. (1994). Romantic involvement, selfdiscrepancy, and psychological well-being: A preliminary investigation. Personal Relationships, 1, 399-404. 
Challman, C. R. (1932). Factors influencing friendships among preschool children. Child Development, 3, 146-158.

Christiano, K.J. (2000). Religion and the family in modern American culture. Family, Religion, and Social Change in Diverse Societies (pp. 43-78). New York. Oxford University Press.

Bouchey, H. A. (2007). Perceived romantic competence, importance of romantic domains, and psychosocial adjustment. Journal of Clinical Child and Adolescent Psychology, 36(4), 503-514.

Christopher, F. S., Johnson, D. C., \& Roosa, M. W. (1993). Family, individual, and social correlates of early Hispanic adolescent sexual expression. Journal of Sex Research, 30, 45-52.

Cochran, M. M., \& Brassard, J. A. (1979). Child development and personal social networks. Child Development, 50(3), 601-616.

Cohen, P., Kasen, S., Chen, H., Hartmark, C., \& Gordon, K. (2003). Variations in Patterns of Developmental Transitions in the Emerging Adulthood Period. Developmental Psychology 39, 657-69.

Cohen, S., \& Wills, T. A. (1985). Stress, social support, and the buffering hypothesis. Psychological Bulletin, 98, 310-357.

Collins, W. A., Christian, S. D., \& Hennighausen, K. (2000, March). "The course of true love(s)...": Longitudinal correlates of occurrence and quality in adolescents' romantic relationships. In I. Seiffge-Krenke (chair), What can the past and future tell us about adolescents' romantic relationships? Symposium.

Connolly, J. \& Goldberg, A. (1999). Romantic relationships in adolescence: the role of friends and peers in their emergence and development. The Development of romantic relationships in adolescence, (pp. 266-290. New York: Cambridge University Press.

Connolly, J. \& McIsaac, C. (2009). Adolescents' explanations for romantic dissolutions: A developmental perspective. Journal of Adolescence, 32, 1209-1223.

Connolly, J., Craig, W., Goldberg, A., \& Pepler, D. (2004). Mixed-gender groups, dating, and romantic relationships in early adolescence. Journal of Research in Adolescence, 14, 185-207. 
Connolly, J., Furman, W., \& Konarski, R. (2000). The role of peers in the emergence of heterosexual romantic relationships in adolescence. Child Development, 71, 13951408 .

Cutrona, C. (1982). Transition to college: Loneliness and the process of social adjustment. In L. Peplau \& D. Perlman (Eds.), Loneliness: A sourcebook of current theory, research and therapy (pp. 291-309). New York: WileyInterscience.

Datnow, A., Hubbard, L., \& Woody, E. (2001). Is single gender schooling viable in the public sector? Lessons from California's pilot program. Retrieved March 19, 2007, from www.oise.utoronto.ca/depts/tps/adatnow/final.pdf

Decter, M. (1995). A Jew in anti-Christian America. First Things, 56, 25-31.

Deniz, M. E., Hamarta, E., \& Ari, R. (2005). An investigation of social skills and loneliness levels of university students with respect to their attachment styles in a sample of Turkish students. Social Behavior and Personality, 33, 19-32.

Dhariwal, A., Connolly, J., Paciello, M., \& Caprara, G. V. (2009). Adolescent peer relationships and emerging adult romantic styles: A longitudinal study of youth in an Italian community. Journal of Adolescent Research, 24, 579-600.

Diehl, M., Coyle, N., \& Labouvie-Vief, G. (1996). Age and sex differences in strategies of coping and defense across the life span. Psychology and Aging, 11, 127-139.

Dillaway, H., \& Broman, C. (2001). Race, class and gender differences in marital satisfaction and divisions of household labor among dual-earner couples. Journal of Family Issues, 22, 309-327.

Dion, K. K., \& Dion, K. L. (1996). Cultural perspectives on romantic love. Personal Relationships, 3, 5-17.

Doherty, R. W., Hatfield, E., Thompson, K., \& Choo, P. (1994). Cultural and ethnic influences on love and attachment. Personal Relationships, 1, 391-398.

Dollahite, D.C. and Marks, L.D. (2005). How highly religious families strive to fulfill sacred purposes. Sourcebook of Family Theory and Research. (pp. 533-541). Thousand Oaks CA: Sage.

El-Or, T. (1994). Educated and ignorant: Ultraorthodox Jewish Women and their world. Boulder, CO: Lynne Rienner Publishers.

Ellis, A. (1988). Is religiosity pathological? Free Inquiry, 18, 27-32. 
Ellison, C. (1990). Family ties, friendships, and subjective well-being among Black Americans. Journal of Marriage and the Family, 52, 298-310.

Erikson, E. H. (1968). Identity, youth and crisis. New York: Norton.

Eysenck, H.J. (1981). A model of personality. New York: Springer.

Feinstein, S.C., \& Ardon, M.S. (1973). Trends in dating patterns and adolescent development. Journal of Youth and Adolescence, 2, 157-166.

Feldman, S. S., \& Rosenthal, D. A. (1990). The acculturation of autonomy expectations in Chinese high-schoolers residing in two western nations. International Journal of Psychology, 25, 259-281.

Freud, S. (1943). A general introduction to psychoanalysis. Garden City, NY: Garden City.

Furman, W. \& Wehner, E. A. (1994). Romantic views: Toward a theory of adolescent romantic relationships. In R. Montemayor, G. R. Adams, and T. P. Gullotta (Eds.), Personal relationships during adolescence. Thousand Oaks, CA: Sage.

George, L.K. (2006). Perceived quality of life. In R.H. Binstock and L.K. George (Eds.) Handbook of aging and the social sciences, 6th ed. San Diego, CA: Elsevier.

Glenn, N.D. (1975). The contribution of marriage to the psychological wellbeing of males and females. Journal of Marriage and the Family 37, 105-110.

Glenn, N.D. \& Weaver, C.N. (1979). A note on family situation and global happiness. Social Forces 57, 960-967.

Gottman, J.M. (1986). The world of coordinated play: Same- and cross-sex friendship in young children. In J.M. Gottman \& J. Parker (Eds), Conversations of friends: Speculations on affective development, (pp. 139-191). New York: Cambridge University Press.

Gove, W.R., Style, C.B. \& Hughes, M. (1990). The effect of marriage on the well-being of adults: A theoretical analysis. Journal of Family Issues 11, 4-35.

Gove, W. R. , \& Umberson, D. (1985). Marriage and the well-being of men and women. Paper presented at the annual meeting of the American Sociological Association, Washington, DC. 
Graham-Bermann, S.A., DeVoe, E.R., Mattis, J.S., Lynch, S., \& Thomas, S.A. (2006). Ecological predictors of traumatic stress symptoms in Caucasian and ethnic minority children exposed to intimate partner violence. Violence Against Women, $12,662-692$.

Green, L. R., Richardson, D. S., Lago, T., \& Schatten-Jones, E. C. (2001). Network correlates of social and emotional loneliness in young and older adults. Personality and Social Psychology Bulletin, 27, 281-288.

Hamon, R. R., \& Ingoldsby, B. B. (2003). Mate selection across cultures. Thousand Oaks: Sage Publications.

Hansen, G. L. (1992). Religion and marital adjustment. In J. F. Schumaker (Ed.), Religion and mental health (pp. 189-198). New York: Oxford University Press.

Heilman, S. C. and Cohen, S. M. 1989. Cosmopolitans \& parochials: Modern Orthodox Jews in America, Chicago: University of Chicago Press.

Heinrich, L. M, \& Gullone, E. (2006). The clinical significance of loneliness: A literature review. Clinical Psychology Review, 26, 695-718.

Hendrick, S. S. (1988). A generic measure of relationship satisfaction. Journal of Marriage and the Family, 50, 93-98.

Hill, P.C., \& Pargament, K.I. (2003). Advances in the conceptualization and measurement of religion and spirituality. American Psychologist, 58, 64-74.

Hobfoll, S. E., \& Spielberger, C. D. (1992). Family stress: Integrating theory and measurement. Journal of Family Psychology, 6, 99-112.

Hoffman, J. A., \& Weiss, B. (1987). Family dynamics and presenting problems in college students. Journal of Counseling Psychology, 34, 157-163.

Hofstede, G. (2001). Culture's consequences: Comparing values, behaviors, institutions and organizations across nations (2nd ed.). Thousand Oaks, CA: Sage.

Holahan, C. J., \& Moos, R. H. (1991). Life stressors, personal and social resources, and depression: A 4-year structural model. Journal of Abnormal Psychology, 100, 3138 .

Holahan, C. J., \& Moos, R. H. (1990). Life stressors, resistance factors, and improved psychological functioning: An extension of the stress resistance paradigm. Journal of Personality and Social Psychology, 58, 909-917. 
Holahan, C. J., \& Moos, R. H. (1987). Risk, resistance, and psychological distress: A longitudinal analysis with adults and children. Journal of Abnormal Psychology, 96, 3-13.

Holahan, C. J., Valentiner, D. P., \& Moos, R. H. (1994). Parental support and psychological adjustment during the transition to young adulthood in a college sample. Journal of Family Psychology, 8(2), 215-223.

Huntington, S. P. (2004). The Hispanic Challenge. Foreign Policy. 30-45.

Huston, T.L., Caughlin, J.P. Houts, R.M. Smith, S.E. , \& George, L.J. (2001). The connubial crucible: Newlywed years as predictors of marital delight, distress, and divorce. Journal of Personality and Social Psychology 80, 237-252.

Hamon, R. R., \& Ingoldsby, B. B. (2003). Mate selection across cultures. Thousand Oaks: Sage Publications.

Ingoldsby, B. (1995). Mate selection and marriage. In B. Ingoldsby \& S. Smith (Eds.), Families in multicultural perspective (pp. 143-160). New York: Guilford.

International Institute for Population Sciences and Population Council. (2010). Youth in India: Situation and needs 2006-2007. Mumbai: International Institute for Population Sciences.

Jackson, J.S., Torres, M., Caldwell, C.H., Neighbors, H.W., Nesse, R.N., Taylor, R.J., Trierweiler, S.J., Williams, D.R. (2004). The National Survey of American Life: A study of racial, ethnic and cultural influences on mental disorders and mental health. IJMPR. 13,4, 96-207.

Jeynes, W. H.(2003).The effects of black and Hispanic $12^{\text {th }}$ graders living in intact families and being religious on their academic achievement. Journal of Urban Education, 38, 35-57.

Johnson, M., \& Milardo, R. (1984). Network interference in pair relationships: A social psychological recasting of Slater's theory of social regression. Journal of Marriage and the Family, 46, 893-899.

Joiner, T. E. (1997). Shyness and low social support as interactive diatheses, with loneliness as mediator: Testing an interpersonal-personality view of vulnerability to depressive symptoms. Journal of Abnormal Psychology, 106, 386-394.

Kahn, R. L., \& Antonucci, T. C. (1980). Convoys over the life course. Attachment, roles, and social support. In P. B. Baltes \& O. G. Brim (Eds.), Life-span development and behavior (pp. 254-283). New York: Academic Press. 
Kamp Dush, C. M. \& Amato, P. B. (2005). Consequences of relationship status and quality for subjective well-being. Journal of Social and Personal Relationships, 22, 607-627.

Kaslow, F. and Robinson, J.A. (1996). Long-term satisfying marriages: Perceptions of contributing factors. American Journal of Family Therapy, 24, 154-170.

Kaufman D R. (1991). Rachel's daughters: Newly Orthodox Jewish women. New Brunswick, NJ: Rutgers.

Kim, H.J., Stiff, J.B., 1991. Social networks and the development of close relationships. Human Communication Research, 18, 70-91.

King, J. E. (1995). Culture-centered knowledge: Black studies, curriculum transformation, and social action. In J. A. Banks \& C. A. M. Banks (Eds.), Handbook of research on multicultural education (pp. 265-292). New York: Macmillan.

Koenig, H.G., Ford, S.M., George, L.K., Blazer, D.G., \& Meador, K.G. (1993). Religion and anxiety disorder: An examination and comparison of associations in young, middle-aged and elderly adults. Journal of Anxiety Disorders, 7, 321-342.

Koenig, H.G., McCullough, M.E., \& Larson, D.B. (2001). Handbook of religion and health. New York: Oxford.

Krause, N. (1991). Stress, religiosity, and abstinence from alcohol. Psychology and Aging, 6, 34-144.

Langston, C. A., \& Cantor, N. (1989). Social anxiety and social constraint: When making friends is hard. Journal of Personality and Social Psychology, 56, 649-661.

Larson, R. W. (1999). The uses of loneliness in adolescence. In K. J. Rotenberg, \& S. Hymel (Eds.), Loneliness in childhood and adolescence (pp. 325-347). Cambridge, England: Cambridge University Press.

Larson, R.W., Wilson, S., Brown, B.B., Furstenberg, F.F., \& Verma, S. (2002). Changes in adolescents' interpersonal experiences: Are they being prepared for adult relationships in the Twenty-first century? Journal of Research on Adolescence, $12,31-68$.

Lehrer, E.L. (2004). The role of religion in union formation: an economic perspective, Population Research and Policy Review 23, 161-185. 
Lei, M., \& Lomax, R.G. (2005). The effect of varying degrees of nonnormality in structural equation modeling. Structural Equation Modeling: A Multidisciplinary Journal, 12 (1), 1-27.

Levitt, M. J. (1991). Attachment and close relationships: A life span perspective. In J. L. Gewirtz \& W. F. Kurtines (Eds.), Intersections with attachment (pp. 183205). Hillsdale, NJ: L. Erlbaum.

Levitt, M. J. (2005). Social relations in childhood and adolescence: The convoy model perspective. Human Development, 48, 28-47.

Levitt, M. J. (2012). Social networks. In Lewis, M., \& Mayes, L. (Eds.), Levitt, M. J. (2012). Social networks. In Lewis, M., \& Mayes, L. (Eds.), The Cambridge handbook of environment in human development (pp. 359-385). New York: Cambridge University Press.

Levitt, M. J., Guacci-Franco, N., \& Levitt, J. L. (1993). Convoys of social support in childhood and early adolescence: Structure and function. Developmental Psychology, 29, 811-818.

Levitt, M. J., Coffman, S., Guacci-Franco, N., \& Loveless (1994). Attachment relations and life transitions: An expectancy model. In M. B. Sperling, \& W. H. Berman (Eds), Attachment in adults: Clinical and developmental perspectives (pp. 232255). New York: Guilford.

Levitt, M. J., Silver, M. E., \& Santos, J. D. (2007). Adolescents in transition to adulthood: Parental support, relationship satisfaction, and post-transition adjustment. Journal of Adult Development, 14, 53-63.

Levitt, M.J. \& Cici Gokaltun, A. (2011). Close relationships across the life span. In K.L. Fingerman, C.A. Berg, J. Smith \& T.C. Antonucci (Eds), Handbook of life-span development. New York: Springer Publishing Company.

Lewis, M., \& Feiring, C. (1979). The child's social network: Social object, social function and their relationship. In M. Lewis \& L. Rosenblum (Eds.), The child and its family system. New York: Plenum Press.

Lewis, M. (1982). The social network model. In T.M. Field, A. Huston, H.C. Quary, L. Troll, \& G.E. Finley (Eds.), Review of human development (pp. 180-214). New York: Wiley.

Lewis, M. (2005). The child and its family: The social network model. Human Development, 48, 8-27. 
Li, Z. H., Connolly, J., Jiang, D., Pepler, D., \& Craig, W. (2010). Adolescent romantic relationships in China and Canada: A cross-national comparison. International Journal of Behavioral Development, 34, 113-120.

Locke, D.C. (1992). Increasing multicultural understanding: A comprehensive model. Newbury Park, CA: Sage Publications.

Logan, S. (1990). Social work practice with black families: A culturally specific perspective. New York: Longman.

Lovibond, S.H.\& Lovibond, P.F. (1995). Manual for the Depression Anxiety Stress Scales (2nd ed.)

Maccoby, E. E. (1998). The two sexes: Growing up apart, coming together. Cambridge, MA: Harvard University Press.

Maccoby, E. E. (1994). Commentary: Gender segregation in childhood. In C. Leaper (Ed.), Childhood gender segregation: Causes and consequences (pp. 87-97). San Francisco: Jossey-Bass.

Mahler, M.S. (1973). On the first three subplanes of the separation-individuation process. International Journal of Psycho-Analysis, 53, 333-338.

Marchand-Reilly, J. F. (2009). Depressive Symptoms in Young Adults: The Role of Attachment Orientations and Romantic Relationship Conflict. Journal of Adult Development, 16, 31-38.

Markides, K. S., \& Martin, H. W. (1979). Predicting self-related health among the aged. Research on Aging, 1, 97-112.

Mastekaasa, A. (1994). Marital Status, Distress, and Well-being: An International Comparison. Journal of Comparative Family Studies 25, 183-205.

Matt, G. E., \& Dean, A. (1993). Social support from friends and psychological distress among elderly persons: Moderator effects of age. Journal of Health and Social Behavior, 34,187-200.

Maughan, B., \& Champion, L. (1990). Risk and protective factors in the transition to young adulthood. In P. B. Baltes \& M. M. Baltes (Eds.), Successful aging: Perspectives from the behavioral sciences (pp. 296-331). Cambridge, England: Cambridge University Press.

McRoy, R. G. (1996). Racial identity issues for black children in foster care. (pp. 131143) Westview Press, Boulder, CO. 
Medora, N. (2003). Mate selection in contemporary India: Love marriages versus arranged marriages. In R. Hamon, \& B. Ingoldsby (Eds.), Mate selection across cultures. (pp. 209-231). Thousand Oaks, CA: SAGE Publications, Inc.

Meier, A. \& Allen, G. (2009). Romantic relationships from adolescence to young adulthood. The Sociological Quarterly, 50, 308-335.

Mickelson K. D., Claffey S. T., Williams S. L. (2006). The moderating role of gender and gender role attitudes on the link between spousal support and marital quality. Sex Roles, 55, 73-82.

Milardo, R. M. (1992). Comparative methods for delineating social networks. Journal of Social and Personal Relationships, 9, 447-461.

Milardo, R., \& Lewis, R. (1985). Social networks, families, and mate selection: A transactional analysis. In L. L'Abate (Ed.), The handbook of family psychology and therapy (pp. 258-283). Homewood, IL: The Dorsey Press.

Milevsky, A. \& Levitt, M. J. (2004) Intrinsic and extrinsic religiosity in preadolescence and adolescence: Effect on psychological adjustment Mental Health, Religion and Culture, 7, 307-321.

Monck, E. (1991). Patterns of confiding relationships among adolescent girls. Journal of Child Psychiatry, 32, 333-345.

Montgomery, M.J., \& Sorell, G.T. (1998). Love and dating experience in early and middle adolescence: Grade and gender comparisons. Journal of Adolescence, 21, 677-689.

Mounts, N. S., Valentiner, D. P., Anderson, K. L., \& Boswell, M. K. (2006). Shyness, sociability, and parental support for the college transition: Relation to adolescents' adjustment. Journal of Youth and Adolescence, 35, 71-80.

Myleme, H., Koenig, H.G., Hays, J.C., Eme-Akwari, A.G., \& Pargament, K.I. (2001). The epidemiology of religious coping: A review of recent literature. International Review of Psychiatry, 13, 86-93.

Neuman, W. (1982). Television and American Culture: The Mass Medium and the Pluralist Audience. Public Opinion Quarterly, 46, 471-487.

No Child Left Behind Act of 2001, 20 U.S.C. 6301 (2001).

Olasky, M. N. (1988). Prodigal press: The anti-Christian bias of the American news media. Westchester, IL. Crossway Books. 
Parks, M.R. \& Adelman, M.B. (1983). Communication networks and the development of romantic relationships: An expansion of uncertainty reduction theory, Human Communication Research, 10, 55-79.

Parks, M.R. Stan, C., \& Eggert, L. (1983). Romantic involvement and social network involvement. Social Psychology Quarterly, 46, 116-130.

Parlee, M. B. (1979). The friendship bond. Psychology Today, 13, 43-54.

Paul, C., Fitzjohn, J., Eberhart-Phillips, J., Herbison, P., \& Dickson, N. (2000). Sexual abstinence at age 21 in New Zealand: The importance of religion. Social Science and Medicine, 51, 1-10.

Paul, E. L., Poole, A., \& Jakubowyc, N. (1998). Intimacy development and romantic status: Implications for adjustment to the college transition. Journal of College Student Development, 39, 75-86.

Peplau, L. A., \& Perlman, D. (1982). Perspectives on loneliness. In L. A. Peplau \& D. Perlman (Eds.), Loneliness: A sourcebook of current theory, research and therapy (pp. 1-18). New York: Wiley.

Perlman, D., \& Landolt, M. A. (1999). Examination of loneliness in children-adolescents and adults: Two solitudes or a unified enterprise? In K. J. Rotenberg, \& S. Hymel (Eds.), Loneliness in childhood and adolescence (pp. 325-347). Cambridge, England: Cambridge University Press.

Pierce, G. R., Sarason, I. G., \& Sarason, B. R. (1991). General and relationship-based perceptions of social support: Are two constructs better than one? Journal of Personality and Social Psychology, 58, 1028-1039.

Podsakoff, P. M., MacKenzie, S. B., Lee, J. Y., \& Podsakoff, N. P. (2003). Common method biases in behavioral research: A critical review of the literature and recommended remedies. Journal of Applied Psychology, 88 (5): 879-903.

Ponzetti, J. J., Jr. (1990). Loneliness among college students. Family Relations, 39, 336340.

Portes A., Rumbaut R.G. (2006). Immigrant America: A portrait. 3rd ed. Berkeley: University of California Press.

Portes A., Rumbaut R.G. (2001). Legacies: The story of the immigrant second generation. Berkeley: University of California Press. 
Poulin, F., Pedersen, S. (2007). Developmental changes in gender composition of friendship networks in adolescent girls and boys. Developmental Psychology, 43, 1484-1495.

Poulson, Eppler, Satterwhite, Wuensch,\& Bass,(1998). Alcohol consumption, strength of religious beliefs and risky sexual behavior in college students. Journal of American College Health, 46, 227-232.

Powlishta, K. K. (1995). Gender segregation among children: Understanding the "Cootie Phenomenon." Young Children, 50, 61-69.

Rashidi, A., \& Rajaram, S.S. (2001). Culture care conflicts among Asian- Islamic immigrant women in U.S. hospitals. Holistic Nursing Practice, 16(1), 55-64.

Rassool, G.H. (2000). The crescent and Islam: Healing, nursing and the spiritual dimension. Some considerations towards an understanding of the Islamic perspectives on caring. Journal of Advanced Nursing, 32(6), 1476-1484.

Rice, K. G., Cole, D. A., \& Lapsley, D. K. (1990). Separation-individuation, family cohesion, and adjustment to college: Measurement validation and a test of a theoretical model. Journal of Counseling Psychology, 37, 195-202.

Riordan, C. (1990). Single gender schools: Outcomes for African and Hispanic Americans. Research in the sociology of education and socialization 18, 177-205. Greenwich, CT. JAI Press.

Robinson, L. C. (1994). Religious orientation in enduring marriage: An exploratory study. Review of Religious Research, 35, 207-217.

Robinson, L. C. \& Blanton, P.W. (1993). Marital strengths in enduring marriages. Family Relations, 42, 38-45.

Rosenberg, M. (1965). Society and the adolescent self-image. Princeton, NJ: Princeton University Press.

Rosenthal, D. A., Gurney, R. M., \& Moore, S. M. (1981). From trust to intimacy:A new inventory for examining Erikson's stages of psychosocial development. Journal of Youth and Adolescence, 10, 525-537.

Rosmarin, D.H., Pargament, K.I., \& Mahoney, A. (2009). The role of religiousness in anxiety, depression and happiness in a Jewish community sample: A preliminary investigation. Mental Health Religion and Culture, 12(2), 97-113. 
Rothbard, J. C., \& Shaver, P. R. (1994). Continuity of attachment across the life span. In M. B. Sperling, \& W. H. Berman (Eds.), Attachment in adults: Clinical and developmental perspectives (pp. 31-71). New York: Guilford Press.

Rowe, K. (2000). Boys and girls perform better at school in single-sex environments. Australian Council for Educational Research.

Rusbult, C. E., \& Van Lange, P. A. M. (1996). Interdependence processes. In E. T. Higgins \& A. Kruglanski (Eds.), Social psychology: Handbook of basic principles (pp. 564-596). New York: Guilford Press.

Russell, D. W., Peplau, L. A., \& Cutrona, C. E. (1980). The revised UCLA loneliness scale: Concurrent and discriminant validity evidence. Journal of Personality and Social Psychology, 8, 41-53.

Sabogal, F., Marin, G., Otero-Sabogal, R., Marin, B. V., \& Perez-Stable, E. (1987). Hispanic familism and acculturation: What changes and what doesn't? Hispanic Journal of Behavioral Sciences, 9, 397-412.

Salomone, R. (2003). Same, different, equal: Rethinking single-sex schooling. New Haven, CT. Yale University Press.

Sanderson, C. A., \& Cantor, N. (1995). Social dating goals in late adolescence: Implications for safer sexual activity. Journal of Personality and Social Psychology, 68, 1121-1134.

Saroglou, V., \& Cohen, A. B. (2011). Psychology of culture and religion: Introduction to the JCCP special issue. Journal of Cross-Cultural Psychology, 42, 1309-1319.

Schmidt, P. R. (1995). Working and playing with others: Cultural conflict in a kindergarten literacy program. The Reading Teacher, 48, 404-412.

Schottenbauer, M. A., Spernak, S. M., \& Hellstrom, I. (2007). Relationship between family religious behaviors and child well-being among third-grade children. Journal of Mental Health, Religion \& Culture, 10(2), 191-198.

Seiffge-Krenke, I. (2003). Testing Theories of Romantic Development from Adolescence to Young Adulthood: Evidence of Developmental Sequence. International Journal of Behavioral Development 27, 519-31.

Spanier, G. B. (1976). Measuring dyadic adjustment: New scales for assessing the quality of marriage and similar dyads. Journal of Marriage and the Family, 38, 15-28.

Sprecher, S. (1998). Insiders' perspective on reasons for attraction to a close other. Social Psychology Quarterly, 61, 287-300. 
Stepick, A., Dutton-Stepick, C., \& Vanderkooy, P. (2011). Becoming American. In S. J. Schwartz, K. Luyckx, \& V. L. Vignoles (Eds.),Handbook of identity theory and research (pp. 867-893). New York, NY: Springer .

Strawbridge, W. J., Shema, S. J., Cohen, R. D., \& Kaplan, G. A. (2001). Religious attendance increases survival by improving and maintaining good health behaviors, mental health, and social relationships. Annals of Behavioral Medicine, 23, 68-74.

Sullivan, K.T. (2001). Understanding the relationship between religiosity and marriage: An investigation of the immediate and longitudinal effects of religiosity on newlywed couples. Journal of Family Psychology, 15, 610-626.

Sullivan, H.S. (1953) Conceptions of modern psychiatry. New York: W.W. Norton \& Company, Inc.

Sullivan, H. S. (1953). The interpersonal theory of psychiatry. New York: Norton.

Surra, C. A., \& Milardo, R. M. (1991). The social psychological context of developing relationships. In W. H. Jones \& D. Perlman (Eds.), Advances in personal relationships (Vol. 3, pp. 1-36). London: Jessica Kingsley.

Sussman, M.B. 1953. The Help Pattern in the Middle Class Family. American Sociological Review, 18, 22-28.

Takahashi, K. (2005). Toward a life span theory of close relationships: The affective relationships model. Human Development, 48, 48-66.

Takahashi,K., Ohara, N. Antonucci, T.C., \& Akiyama, H. (2002). Commonalities and differences in close relationships among the Americans and Japanese: A comparison by the individualism/collectivism concept. International Journal of Behavioral Development, 26, 453-465.

Taylor, R.J., Chatters, L.M., \& Jackson, J.S. (1993). A profile of familial relations among three generation Black families. Family Relations, 42, 332-341.

Taylor, R., Chatters, L., Tucker, M., \& Lewis, E. (1990). Developments in research on Black families: A decade review. Journal of Marriage and the Family, 542, 9931014.

Thompson, M.G. \& Heller, K. (1990). Facets of support related to well-being: Quantitative social isolation and perceived family support in a sample of elderly women. Psychology and Aging, 5(4), 535-544. 
Thornton, A., \& Camburn, D. (1989). Religious participation and adolescent sexual behaviors and attitudes. Journal of Marriage and the Family, 51, 641-653.

Vaillant, C.O. \& Vaillant, G.E. (1993). Is the u-curve of marital satisfaction an illusion? A 40-year study of marriage. Journal of Marriage and Family, 55, 230-239.

Veenhoven, R. (1984). Conditions of happiness. Dordrecht, the Netherlands: Reidel.

Vygotsky, L. S. (1978). Mind in society: The development of higher psychological processes. Cambridge, MA: Harvard University Press.

Watlington, C.G., \& Murphy, C.M. (2006). The roles of religion and spirituality among African American survivors of domestic violence. Journal of Clinical Psychology, 62, 837-857.

Wilcox, R. (1997). Introduction to robust estimation and hypothesis testing. San Diego: Academic Press.

Wilcox, R. (1999). Fundamentals of modern statistical methods. New York: Springer.

Wilcox, R. (2003). Applying contemporary statistical techniques. San Diego: Academic Press.

Wilcox, W.B. (2004). Soft patriarchs, new men: How Christianity shapes fathers and husbands. Chicago, IL: University of Chicago Press.

Williams, D. G. (1988). Gender, marriage, and psychosocial well-being. Journal of Family Issues, 9(4), 452-468.

Williams, D.R., Larson, D.B., Buckler, R.E., Heckmann, R.C., \& Pyle, C.M. (1991). Religion and psychological distress in a community sample. Social Science and Medicine, 32, 1257-1262. 
Table 1

Study 2: Participant Country of Birth

\begin{tabular}{|c|c|c|c|c|c|c|c|c|}
\hline Country & $\mathrm{N}$ & $\%$ & Country & $\mathrm{N}$ & $\%$ & Country & $\mathrm{N}$ & $\%$ \\
\hline Angola & 2 & 0.1 & Guyana & 3 & 0.2 & United States & 1085 & 68.8 \\
\hline Argentina & 3 & 1.0 & Haiti & 18 & 1.1 & Uruguay & 1 & 0.1 \\
\hline Armenia & 3 & 0.2 & Honduras & 15 & 0.7 & Uzbekistan & 3 & 0.2 \\
\hline Aruba & 2 & 0.1 & Hong Kong & 1 & 0.1 & Venezuela & 59 & 3.7 \\
\hline Australia & 1 & 0.1 & Hungary & 1 & 0.1 & Vietnam & 1 & 0.1 \\
\hline Bahamas & 1 & 0.1 & India & 6 & 0.4 & & & \\
\hline Bangladesh & 1 & 0.1 & Iran & 1 & 0.1 & & & \\
\hline Belize & 1 & 0.1 & Israel & 2 & 0.1 & & & \\
\hline Bolivia & 1 & 0.1 & Jamaica & 9 & 0.6 & & & \\
\hline Brazil & 11 & 0.7 & Japan & 2 & 0.1 & & & \\
\hline Canada & 3 & 0.2 & Jordan & 1 & 0.1 & & & \\
\hline Caribbean & 1 & 0.1 & Lebanon & 3 & 0.2 & & & \\
\hline Cayman Islands & 2 & 0.1 & Mexico & 11 & 0.7 & & & \\
\hline Chile & 6 & 0.4 & Moldova & 1 & 0.1 & & & \\
\hline China & 1 & 0.1 & Netherlands & 1 & 0.1 & & & \\
\hline Colombia & 53 & 3.3 & Nicaragua & 15 & 0.9 & & & \\
\hline Congo & 1 & 0.1 & Nigeria & 15 & 0.9 & & & \\
\hline Costa Rica & 4 & 0.3 & Philippines & 6 & 0.4 & & & \\
\hline Cuba & 119 & 7.5 & Pakistan & 2 & 0.1 & & & \\
\hline Dominican Republic & 9 & 0.6 & Panama & 6 & 0.4 & & & \\
\hline Ecuador & 11 & 0.7 & Paraguay & 2 & 0.1 & & & \\
\hline Egypt & 2 & 0.1 & Peru & 18 & 3.6 & & & \\
\hline El Salvador & 5 & 0.3 & Puerto Rico & 16 & 1.0 & & & \\
\hline England & 3 & 0.2 & South Africa & 1 & 0.1 & & & \\
\hline France & 1 & 0.1 & South Korea & 1 & 0.1 & & & \\
\hline Germany & 5 & 0.3 & Spain & 4 & 0.3 & & & \\
\hline Guatemala & 3 & 0.2 & Switzerland & 1 & 0.1 & & & \\
\hline
\end{tabular}


Table 2

Study 1:Means and Standard Deviation of Variables

\begin{tabular}{lcc}
\hline Variable & Mean & SD \\
\hline Years Married & 6.51 & 5.48 \\
Cross-Sex Experience (CSE) & 64.31 & 18.90 \\
Dyadic Adjustment Scale (DAS) & 114.00 & 3.50 \\
Depression, Anxiety and Stress Scale (DASS) & 20.13 & \\
\hline
\end{tabular}


Table 3

Study 1: Correlation Coefficient Values (Pearson) of Variables

\begin{tabular}{|c|c|c|c|c|c|c|}
\hline & Gender & Years Married & Denomination & CSE & MS & DASS \\
\hline Gender & -- & & & & & \\
\hline Years Married & -.037 & -- & & & & \\
\hline Denomination & -.026 & .046 & -- & & & \\
\hline CSE & $-.189 * *$ & .021 & -.081 & -- & & \\
\hline MS & -.059 & $-.230 * *$ & -.050 & -.052 & -- & \\
\hline DASS & .109 & -.014 & -.008 & .007 & $-.291 * *$ & -- \\
\hline
\end{tabular}

$N=250 . * *$. Correlation is significant at the 0.01 level (two-tailed) 
Table 4

Study 1: 95\% Confidence Intervals for Unstandardized Path Coefficients.

\begin{tabular}{lrr}
\hline $\begin{array}{l}\text { Path } \\
\text { Denomination to CSE }\end{array}$ & Point Estimate & $95 \%$ CI \\
Gender to CSE & -19.9 & -25.0 to -14.8 \\
CSE to Marital Satisfaction & -9.1 & -16.0 to -2.2 \\
Gender to Marital Satisfaction & -.06 & -.16 to .04 \\
Years married to Marital Satisfaction & -4.2 & -10.7 to 2.3 \\
Marital Satisfaction to Adjustment & -.796 & -1.2 to -.39 \\
\hline
\end{tabular}


Table 5

Study 2: Means and Standard Deviation of Variables.

\begin{tabular}{lcc}
\hline Variable & Mean & SD \\
\hline Religious Norms & 36.59 & 7.98 \\
Cultural Norms & 36.86 & 7.64 \\
Family Norms & 31.95 & 8.79 \\
Cultural Support & 20.13 & 3.50 \\
Family Support & & 3.34 \\
Cross Sex Experience (CSE) & 22.32 & 8.46 \\
Relationship Assessment Scale (RAS) & & 6.87 \\
Depression, Anxiety and Stress Scale (DASS) & 27.06 & \\
\hline
\end{tabular}


Table 6

Study 2:Correlation Coefficient Values (Pearson) of Variables

\begin{tabular}{|c|c|c|c|c|c|c|c|c|}
\hline & $\begin{array}{l}\text { Religious } \\
\text { Norms }\end{array}$ & $\begin{array}{l}\text { Cultural } \\
\text { Norms }\end{array}$ & $\begin{array}{l}\text { Family } \\
\text { Norms }\end{array}$ & $\begin{array}{l}\text { Cultural } \\
\text { Support }\end{array}$ & $\begin{array}{l}\text { Family } \\
\text { Support }\end{array}$ & $\begin{array}{l}\text { Cross-Sex } \\
\text { Experience }\end{array}$ & $\begin{array}{l}\text { Relationship } \\
\text { Satisfaction }\end{array}$ & Adjustment \\
\hline $\begin{array}{l}\text { Religious } \\
\text { Norms }\end{array}$ & -- & & & & & & & \\
\hline $\begin{array}{l}\text { Cultural } \\
\text { Norms }\end{array}$ & $.714 * * *$ & -- & & & & & & \\
\hline $\begin{array}{l}\text { Family } \\
\text { Norms }\end{array}$ & $.605 * * *$ & $.621 * * *$ & -- & & & & & \\
\hline $\begin{array}{l}\text { Cultural } \\
\text { Support }\end{array}$ & -.006 & -.019 & $-.052 *$ & -- & & & & \\
\hline $\begin{array}{l}\text { Family } \\
\text { Support }\end{array}$ & $.069 * *$ & $.104 * * *$ & $.094 * * *$ & $.320 * * *$ & -- & & & \\
\hline $\begin{array}{l}\text { Cross-Sex } \\
\text { Experience }\end{array}$ & $.119 * * *$ & $.087 * *$ & $.098 * * *$ & $.229 * * *$ & $.210 * * *$ & -- & & \\
\hline $\begin{array}{l}\text { Relationship } \\
\text { Satisfaction }\end{array}$ & .023 & $.049 *$ & $.064 *$ & $.122 * * *$ & $.101 * * *$ & $.154 * * *$ & -- & \\
\hline Adjustment & $-.089 * * *$ & $-.096 * *$ & $-.096 * *$ & $-.147 * * *$ & $-.287 * * *$ & -.047 & $-.159 * * *$ & -- \\
\hline
\end{tabular}

$\mathrm{N}=1,533 .{ }^{*} \mathrm{p}<.05, * * \mathrm{p}<.01, * * * \mathrm{p}<.001$ (two-tailed) 
Table 7

Study 2: 95\% Confidence Intervals for Unstandardized Path Coefficients.

\begin{tabular}{|c|c|c|}
\hline Path & Point Estimate & $95 \% \mathrm{CI}$ \\
\hline Family CSE Norms to CSE & .04 & .02 to .10 \\
\hline Religious CSE Norms to CSE & .08 & -.02 to .14 \\
\hline Family Support to CSE & .37 & .24 to .50 \\
\hline Cultural Support to CSE & .45 & .33 to .57 \\
\hline Family CSE Norms to Relationship Satisfaction & .04 & .002 to. 08 \\
\hline Family Support to Relationship Satisfaction & .09 & -.02 to .20 \\
\hline Cultural Support to Relationship Satisfaction & .16 & .06 to .26 \\
\hline CSE to Relationship Satisfaction & .09 & .05 to .13 \\
\hline Family Support to Adjustment & -1.6 & -1.9 to -1.3 \\
\hline Cultural Support to Adjustment & -.32 & -3.42 to 2.7 \\
\hline Cultural CSE Norms to Adjustment & -.18 & -.31 to .05 \\
\hline Relationship Satisfaction to Adjustment & -.38 & -.53 to -.23 \\
\hline
\end{tabular}


Figure 1. Study 1: Hypothesized SEM Model.

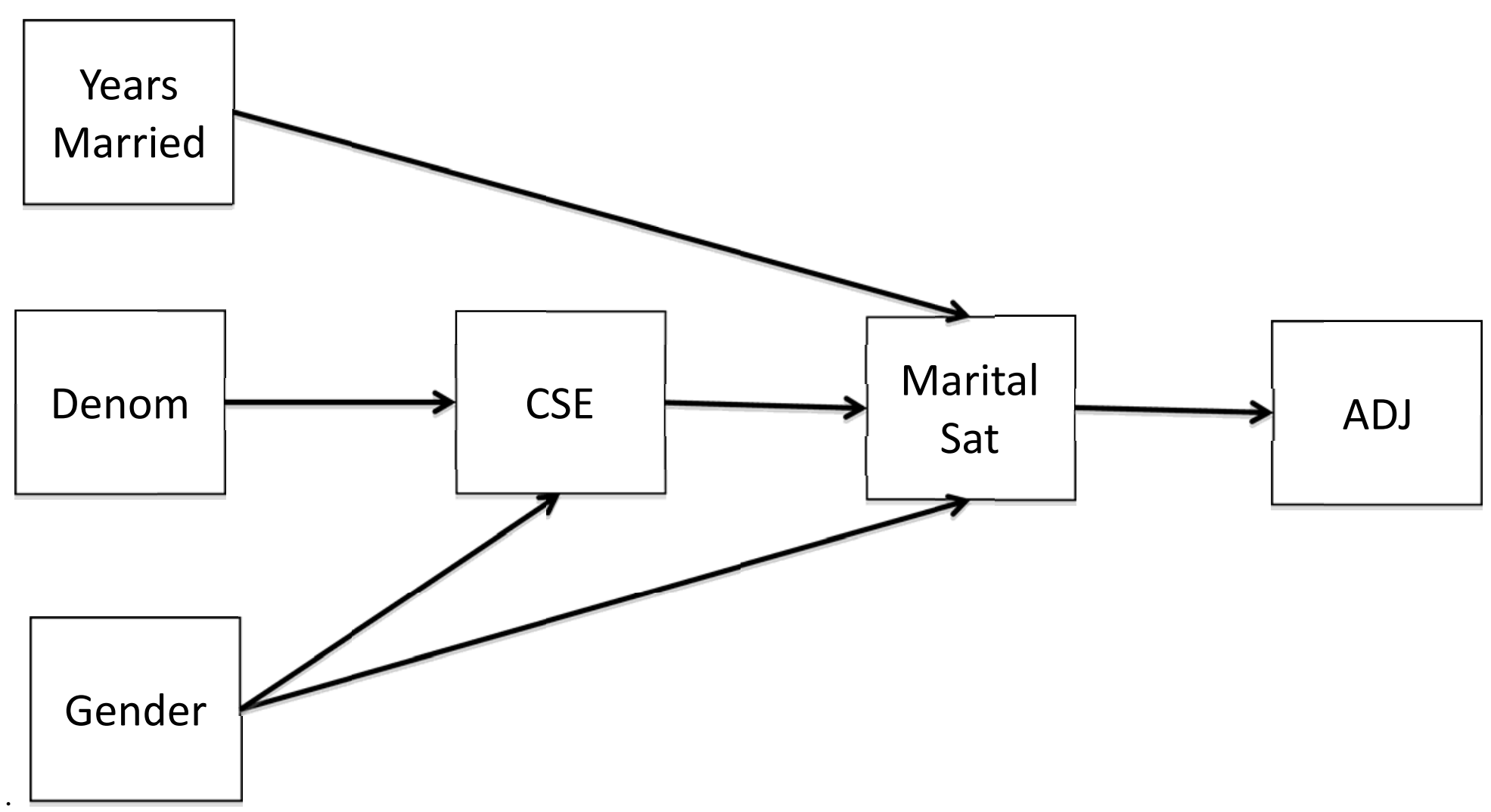


Figure 2.

Study 1: SEM Model with Standardized (and Unstandardized) Path Coefficients.

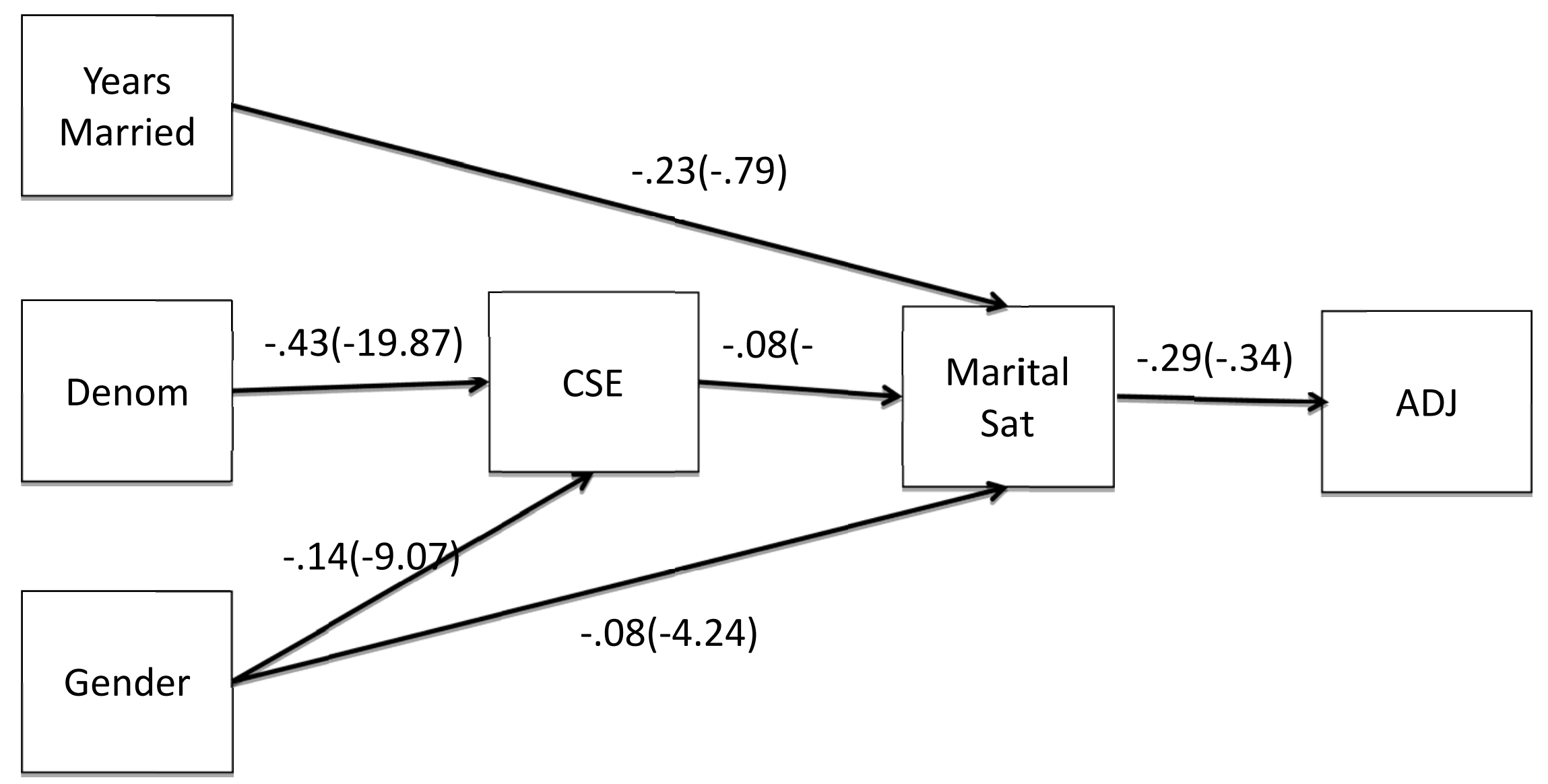


Figure 3.

Study 2: Hypothesized SEM Model.

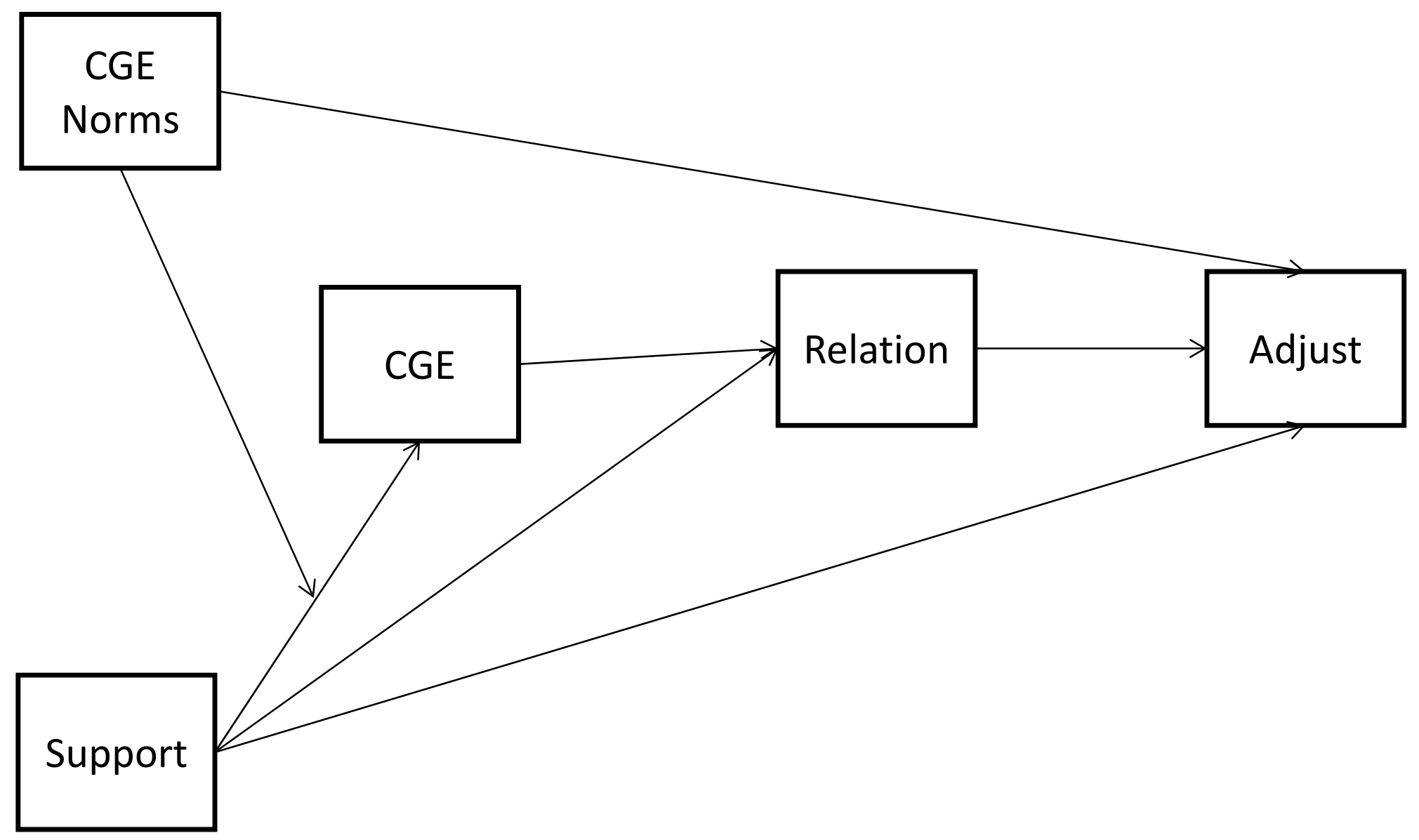


Figure 4. Study 2: Final SEM Model.

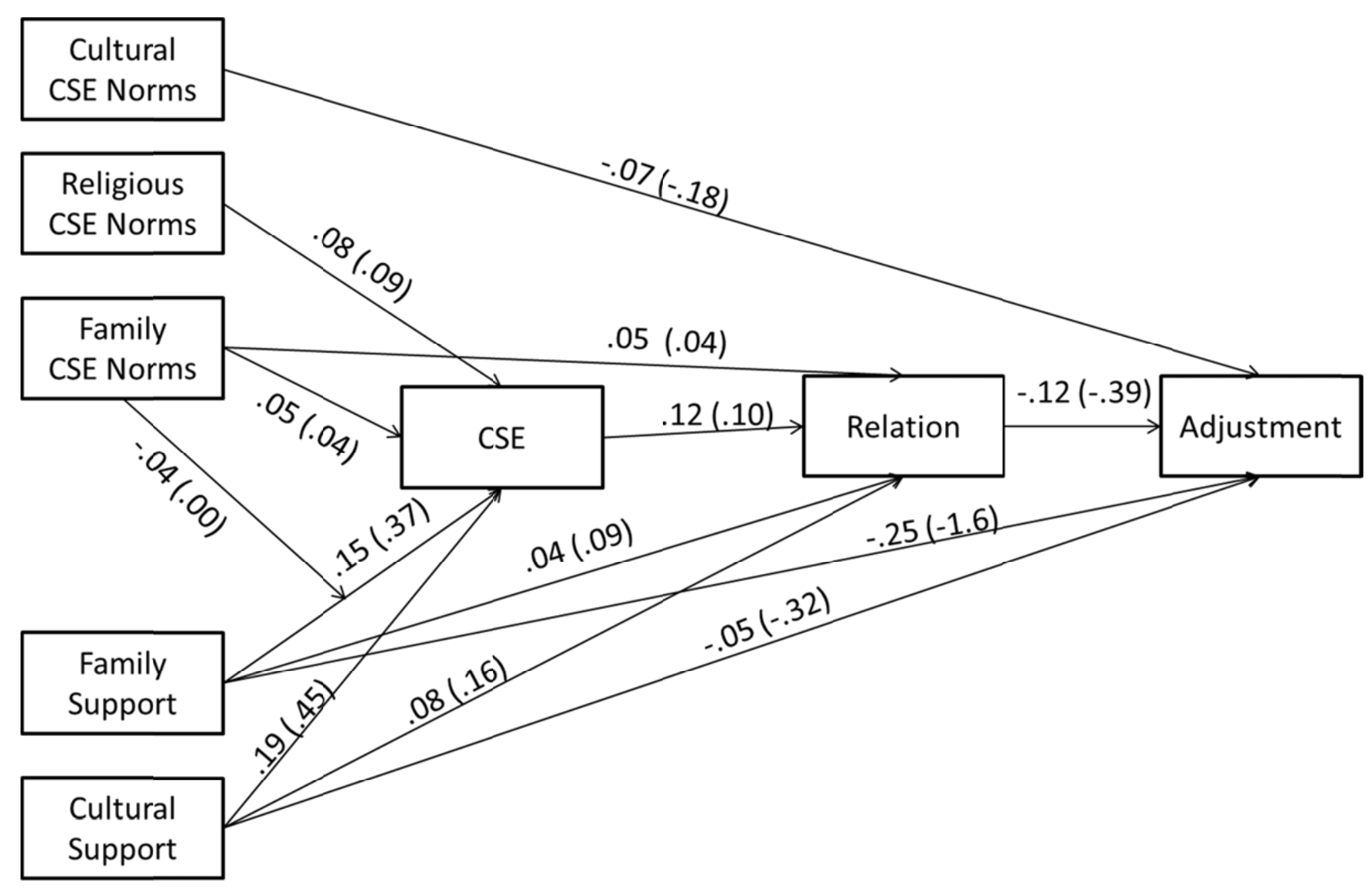




\section{APPENDIX}

\section{Dissertation Survey (Study 2)}

\section{SECTION 1: SOCIAL INTERACTION EXPERIENCE}

\section{Cross-Gender Experience Scale}

The following items refer to your educational experiences. A Same Gender classroom refers to a classroom with only male students (if you are a male), or only female students (if you are a female). A Mixed Gender classroom refers to a classroom with both male and female students. Click on Both if you had some Same Gender classes and some Mixed Gender classes within the same timeframe.

TIMEFRAME

1. Early childhood (ages 3-5)

Both

2. Elementary School (ages 6-11)

Both

3. Middle School (ages 12-14)

Both

4. High School (ages 15-18)

Both
Same Gender

Same Gender

Same Gender

Same Gender

\section{CLASSROOM TYPE}

Mixed Gender

Mixed Gender

Mixed Gender

Mixed Gender

5. How many siblings do you have of the opposite gender?

A number of statements which people used to describe their social interactions are listed below. Read each statement and choose the number that best describes how often you engaged in the activity while you were growing up (during childhood, age 5-11, and/or adolescence, age 12-18).

For example, if you engaged in the activity very frequently choose 1; if you never engaged in the activity choose 5. Use numbers 2-4 to indicate how often you engaged in the activity, if it was less than very frequently. Do not spend too much time on any one statement; simply choose the option that best describes your experiences during your childhood and adolescence.

\begin{tabular}{lrrrr}
\multicolumn{2}{l}{ Very frequently } & & Never \\
1 & 2 & 3 & 4 & 5 \\
\hline
\end{tabular}


6. I conversed with my extended family of the opposite gender.

7. I spent time with my extended family of the opposite gender.

8. I spent vacations or holidays together with members of my extended family of the opposite gender.

9. I used email or social networking sites to interact with my extended family of the opposite gender.

10. I had friends during childhood (age 5 to 11) of the opposite gender.

11. I had friends during adolescence (age 12-18) of the opposite gender.

12. I used email or social networking sites to interact with friends of the opposite gender.

13. I participated in groups or clubs during childhood that included members of the opposite gender.

14. I participated in groups or clubs during adolescence that included members of the opposite gender.

(Questions 15-18 refer to your experiences during adolescence and do not refer to a current partner)

15. I dated members of the opposite gender.

16. I was involved in a serious relationship with a member of the opposite gender.

17. I experienced intimacy (kissing, touching, holding hands) with a member of the opposite gender.

18. I experienced sexual intercourse with a member of the opposite gender.

\section{Romantic Involvement - NSBA}

19. Are you currently married, living with a partner, separated, divorced, widowed or have you never been married?

1. Married

2. Partner

3. Separated

4. Divorced

5. Widowed

6. Never Married

20. If you are married, how long have you been married? MONTHS YEARS

21. If you are not currently married, what do you think the likelihood is that you will ever get married/re-married? 
1. Highly likely

2. Somewhat likely

3. Somewhat unlikely

4. Highly unlikely

22. If you are not married, do you have a main romantic involvement at this time?

1. Yes

2. No

23.. If Yes...How long have you been in that relationship?

MONTHS _ Y YEARS

24. If No ... How much do you want a Main Romantic Involvement?

1. Very Much

2. Somewhat

3. Very Little

4. Not at All

IF NO CURRENT INVOLVEMENT, SKIP TO SECTION 2

\section{Relationship Assessment Scale}

The following questions are about your relationship with your current partner (or about your relationship with your spouse if you are married):

\begin{tabular}{|c|c|c|}
\hline & Low & High \\
\hline $\begin{array}{l}\text { 1. How well does your partner meet your } \\
\text { needs? }\end{array}$ & 1 & 5 \\
\hline $\begin{array}{l}\text { 2. In general, how satisfied are you with } \\
\text { your relationship? }\end{array}$ & 1 & 5 \\
\hline $\begin{array}{l}\text { 3. How good is your relationship } \\
\text { compared to most? }\end{array}$ & 1 & 5 \\
\hline $\begin{array}{l}\text { 4. How often do you wish you hadn't } \\
\text { gotten into this relationship? }\end{array}$ & 1 & 5 \\
\hline $\begin{array}{l}\text { 5. To what extent has your relationship } \\
\text { met your original expectations? }\end{array}$ & 1 & 5 \\
\hline
\end{tabular}




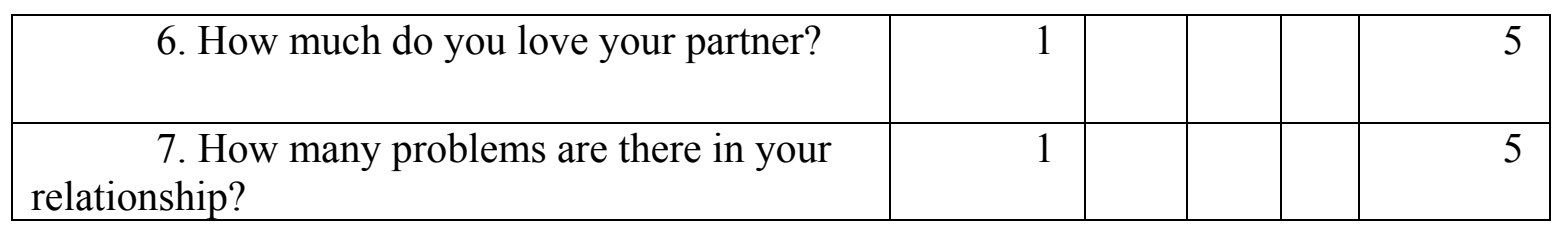

$* 4 \& 7$ reverse scored. Higher score=higher satisfaction

\section{SECTION 2: RELIGIOUS EXPERIENCE}

What is your main religious background? (What was the main religion in your family while you were growing up)?

Do you have the same religion now?

1. Yes

2. No

If no, what is your current religion? (SAME LIST AS ABOVE)

Different religions often have different beliefs and practices regarding social interaction. For each of the following statements, please answer in terms of the main religion that you were raised with.

Indicate whether each statement is completely true, very true, somewhat true, somewhat untrue, very untrue, or completely untrue of the main religion you were raised with.

1. Parents are encouraged to send their children to same sex schools.

2. Children almost always attend same sex elementary schools.

3. Adolescents almost always attend same sex high schools.

4. Adolescents are allowed to date members of the opposite gender of their choosing.

5. Adolescents are prohibited from dating members of the opposite gender of their choosing.

6. Young people are expected to live with their parents until marriage.

7. Young people are encouraged to leave home and to be independent

8. Young people are expected to date only people of the same religion.

9. Sexual intercourse before marriage is strictly prohibited.

10. Young people are expected to marry someone of the same religion.

How important was religion in your home while you were growing up? Was it very important, fairly important, not too important, or not important at all?

1. Very important 
2. Fairly important

3. Not too important

4. Not important at all

How close do you personally feel in your ideas and feelings about things to the beliefs and practices taught in your religion?
5. Very close
6. Fairly close
7. Not too close
8. Not close at all

How important is religion in your life now?

1. Very important

2. Fairly important

3. Not too important

4. Not important at all

Do you currently attend any services or other activities at a place of worship (church, kingdom hall, mosque, synagogue, etc.)?

1. Yes

2. No: SKIP TO SECTION 3

How close do you feel to the people at your place of worship?

$$
\begin{aligned}
& 1 \text { - Very close } \\
& 2 \text { - Fairly close } \\
& 3 \text { - Not too close } \\
& 4 \text { - Not close at all }
\end{aligned}
$$

How satisfied are you with the quality of the relationships you have with the people in your place of worship?

$$
\begin{aligned}
& 1 \text { - Very satisfied } \\
& 2 \text { - Somewhat satisfied } \\
& 3 \text { - Somewhat dissatisfied } \\
& 4 \text { - Very dissatisfied }
\end{aligned}
$$

\section{Received Emotional Support/Negative Interaction - Fetzer}

How often do the people in your place of worship make you feel loved and cared for?

1. Very often

2. Fairly often

3. Not too often

4. Never 
How often do the people in your place of worship listen to you talk about your private problems and concerns?

1. Very often

2. Fairly often

3. Not too often

4. Never

How often do the people in your place of worship express interest and concern in your well-being?

1. Very often

2. Fairly often

3. Not too often

4. Never

How often do the people in your place of worship make too many demands on you?

1. Very often

2. Fairly often

3. Not too often

4. Never

How often do the people in your place of worship criticize you and the things you do?

1. Very often

2. Fairly often

3. Not too often

4. Never

\section{SECTION 3: CULTURAL/ETHNIC EXPERIENCE}

\section{Ethnic Identification}

In this country, people come from many different countries and cultures. And there are many different ways to describe the different backgrounds or ethnic/cultural groups that people come from.

Some examples of the names of ethnic/cultural groups are Cuban or CubanAmerican, Mexican or Mexican-American, African or African-American, Haitian or Haitian-American, Chinese or Chinese-American, Indian, Pakistani, Anglo-American, Spanish, Italian, Russian, Native-American, and many others.

The following questions refer to your ethnic/cultural group.

First, what term would you use to describe your ethnic/cultural group (the one you most identify with)? 


\section{Ethnic/Cultural Norms}

Different ethnic/cultural groups often have different beliefs and practices regarding social interaction. For each of the following statements, please answer in terms of your ethnic/cultural group (the one you most identify with).

Indicate whether each statement is completely true, very true, somewhat true, somewhat untrue, very untrue, or completely untrue of your ethnic/cultural group.

1. Parents are encouraged to send their children to same sex schools.

2. Children almost always attend same sex elementary schools.

3. Adolescents almost always attend same sex high schools.

4. Adolescents are allowed to date members of the opposite gender of their choosing.

5. Adolescents are prohibited from dating members of the opposite gender of their choosing.

6. Young people are expected to live with their parents until marriage.

7. Young people are encouraged to leave home and to be independent

8. Young people are expected to date only people of the same ethnic group.

9. Sexual intercourse before marriage is strictly prohibited.

10. Young people are expected to marry someone of the same ethnic group.

How important was being part of your ethnic/cultural group in your home while you were growing up?

1. Very important

2. Fairly important

3. Not too important

4. Not important at all

How close do you personally feel in your ideas and feelings about things to the beliefs and practices of your ethnic/cultural group?

1. Very close

2. Fairly close

3. Not too close

4. Not close at all

How important is being part of your ethnic/cultural group in your life now?

1. Very important

2. Fairly important 
3. Not too important

4. Not important at all

Do you currently belong to any clubs or organizations specifically for members of your ethnic/cultural group?

1. Yes

2. No

Not counting your family, how close do you feel to other people in your ethnic/cultural group?

1. Very close

2. Fairly close

3. Not too close

4. Not close at all

Not counting your family, how satisfied are you with the quality of the relationships you have with other people in your ethnic/cultural group?

1. Very satisfied

2. Somewhat satisfied

3. Somewhat dissatisfied

4. Very dissatisfied

\section{Support/Negative interaction}

Not counting your family:

How often do the people in your ethnic/cultural group make you feel loved and cared for?

1. Very often

2. Fairly often

3. Not too often

4. Never

How often do other people in your ethnic/cultural group listen to you talk about your private problems and concerns?

1. Very often

2. Fairly often

3. Not too often

4. Never

How often do other people in your ethnic/cultural group express interest and concern in your well-being? 
5. Very often

6. Fairly often

7. Not too often

8. Never

How often do the people in your ethnic/cultural group make too many demands on you?

1. Very often

2. Fairly often

3. Not too often

4. Never

How often do the people in your ethnic/cultural group criticize you and the things you do?

1. Very often

2. Fairly often

3. Not too often

4. Never

\section{SECTION 4: FAMILY EXPERIENCE}

Now we would like to know about your family's beliefs and practices. For each of the following statements, please indicate whether the statement is completely true, very true, somewhat true, somewhat untrue, very untrue, or completely untrue of your family experience.

1. As an adolescent, I was allowed to date members of the opposite gender of my choosing.

2. As an adolescent, I was prohibited from dating members of the opposite gender of my choosing.

3. I was expected to live with my parents until marriage.

4. I was encouraged to leave home and to be independent

5. I was expected to date only people from my own religion.

6. I was expected to date only people from my own ethnic/cultural group

7. Sexual intercourse before marriage was strictly prohibited.

8. I was expected to marry someone from my own religion.

9. I was expected to marry someone from my own ethnic/cultural group.

The following questions refer to family members other than a spouse or partner:

How close do you personally feel in your ideas and feelings about things to the beliefs and practices of your family?

1. Very close

2. Fairly close

3. Not too close 
4. Not close at all

Overall, how close do you feel to the people in your family?

1. Very close

2. Fairly close

3. Not too close

4. Not close at all

How satisfied are you with the quality of the relationships you have with the people in your family?

1. Very satisfied

2. Somewhat satisfied

3. Somewhat dissatisfied

4. Very dissatisfied

How often do the people in your family make you feel loved and cared for?

1. Very often

2. Fairly often

3. Not too often

4. Never

How often do the people in your family listen to you talk about your private problems and concerns?

1. Very often

2. Fairly often

3. Not too often

4. Never

How often do the people in your family express interest and concern in your wellbeing?

1. Very often

2. Fairly often

3. Not too often

4. Never

How often do the people in your family make too many demands on you?

1. Very often

2. Fairly often

3. Not too often

4. Never

How often do the people in your family criticize you and the things you do?

1. Very often

2. Fairly often

3. Not too often

4. Never 


\section{Depression Anxiety Stress Scale (DASS-21)}

Please read each statement and choose the answer that indicates how much the statement applied to you OVER THE PAST 3 MONTHS. There are no right or wrong answers. Do not spend too much time on any statement. Check the appropriate circle using the following rating scale:

$\mathbf{0}=$ Did not apply to me at all

$\mathbf{1}=$ Applied to me to some degree, or some of the time

$\mathbf{2}=$ Applied to me a considerable degree, or a good part of the time $3=$ Applied to me very much, or most of the time

I was aware of dryness of my mouth

I found it hard to wind down

I couldn't seem to experience any positive feeling at all

I experienced breathing difficulty (e.g., excessively breathing, breathlessness in the absence of physical exertion)

I found it difficult to work up the initiative to do things

I tended to over-react to situations

I experienced trembling (e.g., in the hands)

I felt that I was using a lot of nervous energy

I was worried about situations in which I might panic and make a fool of myself

I felt that I had nothing to look forward to

I found myself getting agitated

I found it difficult to relax

I felt down-hearted and blue

I was intolerant of anything that kept me from getting on with what I was doing

I felt I was close to panic

I was unable to become enthusiastic about anything

I felt that I wasn't worth much as a person

I felt I was rather touchy

I was aware of the action of my heart in the absence of physical exertion (e.g., sense of heart rate increasing, missing a beat)

I felt scared without any good reason

I felt that life was meaningless 


\section{DEMOGRAPHICS}

In what year were you born?

In what country were you born?

1. US

2. Other (specify)

In what country was your mother born?

1. US

2. Other (specify)

In what country was your father born?

1. US

2. Other (specify)

Were any of your grandparents born in a country other than the US?

1. Yes

2. No

To which of the following categories does the main religion you grew up with belong?

1. Buddhist

2. Catholic

3. Hindu

4. Jewish

5. Muslim

6. Protestant

If you have a different religion now, to which of the following categories does your current religion belong?

1. Buddhist

2. Catholic

3. Hindu

4. Jewish

5. Muslim

6. Protestant 
In which of the following categories does your ethnic/cultural group best fit?

1. Asian or Asian American, including Chinese, Japanese, Indian, and others

2. Black or African American

3. Black Caribbean (including Jamaican, Bahamian, and others)

4. Black Haitian

5. Hispanic, including Cuban, Mexican American, Central/South American, and others

6. White, Caucasian, Anglo, European American; not Hispanic

7. American Indian/Native American

8. Other (specify)

9. Mixed (specify)

What is your biological gender?

1. Male

2. Female

What is your primary sexual orientation/identification?

1. Heterosexual

2. LGBT (Lesbian, gay, bi-sexual, or transsexual)

3. Other 
VITA

HOD TAMIR

November 30, 1981

2002-2005

2004-2005

2006-2009

2010-2012

$2012-2015$
Born, Miami, FL

B.A. Hebrew Letters

Chabad Rabbinical College

Miami, FL

Rabbinic Ordination

Chabad Central Yeshiva

Brooklyn, NY

B.A., Psychology; Magna Cum Laude

Touro College South.

Miami, FL.

M.S., Psychology

Florida International University

Miami, FL.

Doctoral Candidate, Psychology

Florida International University, Miami, FL.

\section{PUBLICATIONS AND PRESENTATIONS}

Tamir, H.Y. \& Levitt, M.J. Predictors of Marital Satisfaction in an Orthodox Jewish Sample. (In preparation).

Tubman, J.G., Oshri, A., Tamir, H.Y. Heterogeneity in sexual communication among adolescence receiving substance abuse treatment services: implications for hiv/sti risk reduction efforts. (In press)

Lipskar-Dworkin, S.M. \& Tamir, H.Y. Conformity and Generosity: A Social Experiment on Positive Peer Pressure. Poster presented at the Association for Psychological Science Conference. San Francisco, CA 2014

Hod Y. Tamir \& Mary J. Levitt. Proposed Measure for Cross-Gender Experience in Educational, Familial, Social, and Romantic domains. Poster presented at the Society for Study of Human Development Conference. Ft. Lauderdale, FL 2013 
Hod Y. Tamir \& Mary J. Levitt. Cross-Gender Experience in Childhood and Adolescence in a Religious Context: Relation to Adult Marital Satisfaction and Well-Being. Poster presented at the Society for Research on Child Psychology meeting. Seattle, WA 2013

Tamir, H.Y., \& Levitt, M.J. Parent-Child Relationships and Romantic Involvement in the Transition to Adulthood. Poster presented the Association for Psychological Science conference. Washington, DC 2011

Milevsky, A., Friedman, R., Miller, M. L., Peppard-Becker, Y., Stern, D., Tamir, H.Y., Tropper, A. Parental Competence and Depression in Ultra-Orthodox Jewish Mothers: Mediating Effects of Marital Satisfaction. Poster presented at the Association for Psychological Science conference. Washington, DC 2011

Tamir, H. Y., \& Sacks, M. B. Premarital social interaction and marital satisfaction. Poster presented at the Association of Behavioral and Cognitive Therapy conference. New York, NY, 2009.

Tamir, H. Y., \& Sacks, M. B. Sex segregation within the orthodox Jewish community. Poster presented at the Florida Psychological Association conference. Westin, FL, 2009.

Tamir, H.Y., Tamir, C. M., \& Sacks, M. B. Spirituality and well-being in older adults. Poster presented at Barry University student research conference. Miami, FL, 2007. 